\title{
HCCI Engine Optimization and Control
}

Final Report to the Department of Energy

For the period from January 1, 2002 to December 31, 2004

Submitted: September 30, 2005

PI: Wisconsin Distinguished Prof. Rolf D. Reitz

Engine Research Center (ERC)

University of Wisconsin-Madison

\section{SUBCONTRACTOR(S)/COLLABORATOR(S):}

(ERC): Profs. Rolf Reitz, Dave Foster, Jaal Ghandhi, Kevin Hoag and Chris Rutland (PSU) Penn State University: Prof. Dan Haworth 
Statement of Objectives - The goal of this project was to develop methods to optimize and control Homogeneous-Charge Compression Ignition (HCCI) engines, with emphasis on diesel-fueled engines. HCCI offers the potential of nearly eliminating IC engine NOx and particulate emissions at reduced cost over Compression Ignition Direct Injection engines (CIDI) by controlling pollutant emissions in-cylinder. The project was initiated in January, 2002, and the present report is the final report for work conducted on the project through December 31, 2004.

Periodic progress has also been reported at bi-annual working group meetings held at USCAR, Detroit, MI, and at the Sandia National Laboratories. Copies of these presentation materials are available on CD-ROM, as distributed by the Sandia National Labs. In addition, progress has been documented in DOE Advanced Combustion Engine R\&D Annual Progress Reports for FY 2002, 2003 and 2004. These reports are included as the Appendices in this Final report.

Project Description - The original proposal consisted of 6 experimental and theoretical tasks, as shown in Table 1. In the final accepted proposal, Task 3 was removed, and Tasks 2, 4, 5, and 6 were streamlined and/or removed (shown in italics and strike-out in Table 1). Elements of Task 3.1 were later added under matching funding from Ford (shown in Bold in Table 1).

\section{Table 1 - Project Tasks and PIs}

Task 1 - DI-HCCI Engine Mapping, Optimization and Control Experimental DI-HCCI/GDI Regime Mapping - Reitz (ERC)

1.1 DI-HCCI Engine Computer Optimization - Reitz (ERC)

1.2 DI-HCCI Engine Control System Development - Hoag, Reitz and Rutland (ERC)

Task 2 - Engine System Development

2.1 Full-Cycle Engine Simulation - Hoag and Reitz (ERC)

2.2 HCCI Experiments for Full-Cycle Model Validation - Foster (ERC)

2.3 Artificial neural networks (ANN) Rutland (ERC)*

Task 3 -New and Enabling Technologies

Task 3.1 HCCI Studies with Valve Deactivation - Ghandhi (ERC)

3.2 HCCI Using Variable Valve Actuation Edwards (SU)

Task 4 - Chemical Kinetic Mechanism Development

4.1 HCCI Experiments for Detailed Chemistry Model Validations - Foster (ERC)

4.2 Detailed Chemical Kinetics Validation - Dryer (PrU)

Task 5 - Detailed CFD Modeling

5.1 Model Development and Implementation - Haworth (PSU), Rutland (ERC)

5.2 Model Application - Rutland (ERC), Haworth (PSU)

Task 6 - Fuel Injection Processes

6.1 HCCI Spray Characterization Farrell (ERC)

6.2 Impingenent and Multicomponent Film Vaporization Modeling and Experiments tee (UHC)

6.3 CFD Spray Model Development - Rutland (ERC) 
This report reviews the research milestones and deliverables for the 3 years on the funded projects. Additional work is also described for Task 3.1. Detailed descriptions of progress on each Task are provided in the Appendices.

Task 1 - DI-HCCI Engine Mapping, Optimization and Control

Team Members: Reitz ${ }^{1}$, Hoag, Rutland (ERC)

Industry/DOE Level 1 Partners: Caterpillar, Ricardo, Delphi, DOE Sandia National Laboratories

\section{Description of Research Task and Technical Approach:}

1.1 Experimental DI-HCCI/GDI Regime Mapping - Reitz (ERC): This Task explores the regimes under which HCCI diesel combustion takes place with in-cylinder direct injection (DI). This is necessary to develop a knowledge-based control system, which requires significant knowledge of the effect of engine operating variables on combustion. In addition, once the effect of operating variables is understood, optimization can be applied to achieve satisfactory engine operation over a wide range of operating conditions. Task 1.1 includes optimization using state-of-the-art optimization tools.

1.2 DI-HCCI Engine Computer Optimization - Reitz (ERC): This Task is conducted in conjunction with the experiments of Task 1.1 and focuses on computer optimization of DI-diesel HCCI or PCCI (Premixed Charge Compression Ignition) combustion. The optimization is performed using Genetic Algorithms (GA) that have been combined with multidimensional KIVA modeling and successfully used to optimize diesel engine operating conditions at the ERC.

1.3 DI-HCCI Engine Control System Development - Hoag, Reitz and Rutland (ERC): This task consists of two parts: the selection of appropriate engine performance sensors, and the development of engine control algorithms that use input from sensors to control engine performance. The Caterpillar test cell features fully-automated testing with complete computer control of the engine operating parameters (e.g., load, speed, intake boost pressure, exhaust back pressure, EGR rate, intake temperature, injection pressure, start-of-injection timing, and split injection parameters). Thus, the facility lends itself extremely well for the present control system development effort.

\section{Research Milestones and Deliverables:}

Year 1: Perform experimental exploration of DI-diesel HCCI engine combustion regime boundaries for knowledge-based control system and model development; Apply CFD models for DI-diesel HCCI engines; Evaluate and select engine combustion sensors for engine control - Reitz (ERC); Develop real-time simulation tools for engine control Hoag and Rutland (ERC)

Status: Completed: see Appendix A.

\footnotetext{
${ }^{1}$ Team leaders are listed in Bold Face
} 
Year 2: Perform experimental and CFD analyses of effects of injection strategy (e.g., early/late injection, split injection), intake gas temperature and boost pressure, and EGR on combustion; Apply RSM for experimental optimization of HCCI diesel engine combustion parameters; Apply GA computer modeling technique to optimize HCCI engine control variables in conjunction with experimental RSM optimization - Reitz (ERC); Interface simulation with combustion sensors to correlate/assess combustion regimes - Hoag, Rutland and Reitz (ERC)

Status: Completed: see Appendix B.

Year 3: Define optimum engine operating conditions using CFD and global engine performance models and provide experimental validation of predicted optima - Reitz (ERC); Integrate engine sensor data with global models for HCCI diesel control strategy selection; Test engine control algorithms using engine data from team members - Hoag, Rutland and Reitz (ERC)

Status: Completed: see Appendix C.

\section{Task 2 - Engine System Development}

Team Members: Hoag, Foster, Reitz, Rutland (ERC)

Industry/DOE Level 1 Partners: Caterpillar, Delphi, Ricardo, Yamaha

\section{Description of Research Task and Technical Approach:}

2.1 Full-Cycle Engine Simulation - Hoag, Rutland and Reitz (ERC): Engine simulations have been used to develop global models for optimizing the engine control strategy. The objective is to develop a full-cycle performance model that accurately assesses the potential performance and fuel economy benefits of the DI-diesel HCCI engine. Once the basic model has been developed and validated it is used to set direction for further HCCI engine optimization. It provides a platform for the detailed investigation of such technologies as variable compression ratio, variable valve timing, the use of EGR, and other parameters offering the potential to broaden the practical operating range of HCCI combustion. The development and exercise of this simulation is closely integrated with the controls algorithm development.

2.2 HCCI Experiments for Full-Cycle Model Validation - Foster (ERC): This experimental program is performed primarily on the ERC CFR and a new Yamaha engine operating with well-mixed (i.e., homogeneous charge) diesel fuel, and a variable compression ratio (CR). It is presently unknown to what extent a reasonable operating range for homogeneous charge combustion can be obtained in the CFR and the highspeed Yamaha engines using diesel fuel. Tasks 1.1 and 1.2 concentrate on direct injection (DI) combustion, whereas the present Task 2.2 also considers homogeneous operation. Engine control algorithms developed in Task 2.1 are based on models that incorporate state-of-the-art chemistry and full-cycle performance simulation. Model 
validation is accomplished using data obtained in Task 2.2 over a wide range of engine operation conditions.

\section{Research Milestones and Deliverables:}

Year 1: Develop simplified (global and 1-D) engine combustion models for describing DI-diesel HCCI combustion for use in control algorithms - Hoag, Rutland and Reitz (ERC); Obtain HCCI engine performance data for diesel fuel over a wide range of compression ratios, speeds, loads for system model validation - Foster (ERC); Collect relevant HCCI data and model HCCI cases using KIVA-ERC - Reitz and Rutland (ERC). Status: Completed: see Appendix A

Year 2: Provide estimates of performance and fuel economy benefits of DI-diesel HCCI. Use model as interactive tool for control algorithm development - Hoag, Rutland and Reitz (ERC); Obtain HCCI engine performance data over a wide range of compression ratios, speeds, loads for system model validation - Foster (ERC)

Status: Completed: see Appendix B

Year 3: Complete evaluation of global engine performance models with engine control algorithms - Hoag, Rutland and Reitz (ERC); Obtain HCCI engine performance data over a range of compression ratios, speeds, loads for system model validation - Foster (ERC)

Status: Completed: see Appendix C

\section{Task 3 - New and Enabling Technologies}

This Task was removed from the original proposal. However, funding for related work was obtained from Ford via a URP (University Research Project) in the second year of the project.

Team Members: Ghandhi, Reitz (ERC)

Industry/DOE Level 1 Partners: Ford

\section{Description of Research Task and Technical Approach:}

3.1 Limits to HCCI operation - Ghandhi (ERC): Models of HCCI combustion indicate that combustion efficiency decreases with low equivalence ratio operation. The cause for combustion deterioration and the role of mixing is studied experimentally in Task 3.1. Planar imaging data has been acquired to investigate the HCCI combustion process at the light load limit. The study provides guidelines to extend the load range of HCCI operation.

\section{Research Milestones and Deliverables:}

Year 2: Perform experimental studies of effects of mixture preparation on combustion Ghandhi (ERC);

Status: Completed: see Appendix B 
Year 3: Study effects of mixture preparation on combustion at low load - Ghandhi (ERC);

Status: Completed: see Appendix C

\section{Task 4 - Chemical Kinetic Mechanism Development}

Team Members: Foster (ERC)

Industry/DOE Level 1 Partners: Lawrence Livermore Labs, Yahama

\section{Description of Research Task and Technical Approach:}

4.1 HCCI Experiments for Detailed Chemistry Model Validations - Foster (ERC): Combustion phasing is a key obstacle to successful HCCI engine operation. The start of ignition timing is known to be controlled by the details of hydrocarbon chemistry. This Task evaluates models tailored to be useful for both full-cycle global and detailed CFD models. To maximize the development potential of HCCI combustion one needs to have a sufficiently fundamental understanding of the phenomena so it can be reproduced with simulations. Both gasoline and diesel fuel are being considered using iso-octane and nheptane chemistry mechanisms in order to be able to model cetane and octane number effects.

\section{Research Milestones and Deliverables:}

Year 1: Develop experimental database for both gasoline and diesel chemical kinetic model validation over the range of pressure, temperature and fuel-air ratios of interest in HCCI and GDI. Quantify pre-combustion chemistry - Foster (ERC)

Status: Completed: see Appendix A

Year 2: Compare Global HCCI engine model predictions using reduced chemistry models with engine experimental data - Foster (ERC)

Status: Completed: see Appendix B

Year 3: Validate and apply reduced chemistry schemes in diesel engine system models Foster (ERC)

Status: Completed: see Appendix C

\section{Task 5 - Detailed CFD Modeling}

Team Members: Rutland (ERC), Haworth (PSU)

Industry/DOE Level 1 Partners: Caterpillar, Los Alamos National Laboratories

\section{Description of Research Task and Technical Approach:}


5.1 Model Development and Implementation - Haworth (PSU), Rutland (ERC): The proposed HCCI modeling strategy comprises several advanced features: (1) large-eddy simulation (LES) for turbulence; (2) spray models that are consistent with LES mixing models and DI operating conditions (see Task 6); and (3) combustion and emissions models that include the appropriate level of chemical kinetics (see Tasks 1 and 2). The advanced engine CFD applications establish the use of comprehensive turbulence, mixing, chemistry and spray models for DI engine applications. These advanced, unique capabilities assure sufficient physical fidelity and accuracy so that CFD simulations can provide detailed results for increased understanding.

5.2 Model Application - Rutland (ERC), Haworth (PSU): Baselines are established using the existing CFD codes (KIVA and KIVA-3V) with their existing physical submodels. As each the models of Tasks 5.1 and 6.3 become available, they are integrated into one or both codes, and applied to one or more of the project experimental engines.

\section{Research Milestones and Deliverables:}

Year 1: Perform baseline RANS and LES calculations using existing KIVA for the project engines (PSU, ERC); Develop, implement, and validate the Lagrangian/Eulerian PDF/ISAT modeling framework (PSU); Develop, implement, and test LES models of scalar mixing, spray, and combustion for DI-diesel and PFI-gasoline applications (ERC). Status: Completed: see Appendix A

Year 2: Perform LES through multiple engine cycles to properly account for residual gases on the project engines. Perform detailed comparisons with experimental measurements (PSU, ERC); Continue model and methodology development and implementation, including reduced models suitable for Eulerian formulation (PSU); Continue LES model development and testing; shift emphasis to engine comparisons (ERC, PSU).

Status: Completed: see Appendix B

Year 3: Perform LES and RANS computations of turbulent flow, injection, mixing, autoignition, and combustion with variations in engine operating conditions, geometric configuration (e.g., valve timing and profiles), and fuel-injection strategy (PFI versus DI). Use results to interpret engine experiments and to guide engine and control system design (PSU, ERC).

Status: Completed: see Appendix C

\section{Task 6 - Fuel Injection Processes}

Team Members: Rutland, Reitz (ERC)

Industry/DOE Level 1 Partners: Los Alamos National Laboratory

\section{Description of Research Task and Technical Approach:}


6.3 CFD Spray Model Development - Rutland, Reitz (ERC): The projects of Tasks 6.1 and 6.2 were removed from the proposal. However, the activities of Task 6.2 have been combined with Tasks 1.2, 2.2, 4.1, 5.1 and 5.2. In conjunction with the detailed engine modeling of Tasks 1.2, 4.1, 5.1 and 5.2, spray models have been incorporated into the CFD modeling effort.

\section{Research Milestones and Deliverables:}

Year 1: Adapt and test spray models for HCCI-diesel and GDI conditions; compare results with experimental spray data - Rutland (ERC).

Status: Completed: see Appendix A

Year 2: Integrate existing multi-component fuel models, flash evaporation models, and wall film models with LES codes from task 5; compare with experimental spray data and engine data - Rutland (ERC).

Status: Completed: see Appendix B

Year 3: Compare CFD predictions with experimental spray data - Rutland (ERC).

Status: Completed: see Appendix C 


\title{
APPENDIX A \\ 2002 Annual Progress Report Combustion and Emission Control for Advanced CIDI Engines
}

\author{
Project VII. HCCI \\ D. HCCI Engine Optimization and Control Using Diesel Fuel - R. Reitz, UW
}

Profs. Rolf D. Reitz, Dave Foster, Kevin Hoag and Chris Rutland

1500 Engineering Drive

Madison, WI 53706

Tel: (608) 262-0145, Fax: (608) 262-6707 e-mail: reitz@engr.wisc.edu

Subcontractor:

Prof. D. Haworth, State College, PA

Project start date: 1/1/2002 - Duration: 3 years

DOE Program Manager: Gurpreet Singh

Department of Energy, EE 322

1000 Independence Avenue, SW

Washington, DC 20585

Tel: 202-586-2333, Email: gurpreet.singh@hq.doe.gov

Objectives

- Develop methods to optimize and control Homogeneous-Charge Compression Ignition (HCCI) engines, with emphasis on diesel-fueled engines.

- Use engine experiments and detailed modeling to study factors that influence combustion phasing, unburned hydrocarbon (UHC) and $\mathrm{CO}$ emissions.

- Provide criteria for transition to other engine operation regimes (e.g., standard diesel combustion)

Approach

- Use 2 fully-instrumented engines with prototype fuel injection systems and combustion sensors to map and define HCCI combustion regimes, and apply optimization techniques

- Develop and apply engine performance models, including zero- and 1-D global models for control system development

- Use homogeneous charge CFR engine experiments to document fuel effects on HCCI ignition

- Develop and apply modeling tools, including multi-dimensional codes (e.g., KIVA with state-of-the-art turbulent combustion and detailed chemistry models) to reveal combustion mechanisms 
Accomplishments

- Engine operation at both very early and very late start-of-injection timings has been shown to produce low emissions, with HCCI-like combustion

- A combustion control criterion based on the ignition/injection time delay has been formulated for low emissions operation

- A multidimensional model has been developed and applied successfully to model early and late injection cases.

- HCCI ignition has been shown to be controlled by effects beyond fuel octane number

- Computationally efficient methods to incorporate detailed chemistry submodels have been formulated.

Future Directions

- A prototype high pressure hydraulic unit injector will be implemented to assess the effects of multiple injections on diesel HCCI combustion regimes

- Use of cylinder pressure-based sensing for engine control will be analyzed

- Ignition characteristics of diesel fuel will be explored in engine experiments

- Efficient methods for including detailed kinetics in multidimensional models will be implemented and tested

\section{Introduction}

This project is a response to the Department of Energy (DOE) solicitation for research and development on Homogeneous Charge Compression Ignition (HCCI) diesel-fueled engines. Advantages of HCCI operation include significantly reduced NOx and particulate emissions. However, there are significant challenges associated with the successful operation of HCCI engines. One of the major difficulties is to control the combustion phasing - mainly the assurance of autoignition at appropriate timings over a wide range of operating conditions. Another obstacle of HCCI engine operation is the relatively high emissions of unburned hydrocarbon $(\mathrm{HC})$ and carbon monoxide $(\mathrm{CO})$ due to incomplete combustion with low-temperature lean burn. The power output of the HCCI engine is also limited since the combustion can become unstable, and knock-like cylinder pressure oscillations can occur as the mixture approaches stoichiometric.

\section{Approach}

In order to control the engine, it is necessary to know what variables to control. The five (5) technical tasks of the present work provide information about HCCI combustion mechanisms for use in knowledge-based engine control schemes. The experiments use a fully instrumented Caterpillar 3401 engine that features electronically controlled fuel injection systems to map combustion regimes (Task 1). In this Task combustion sensors are also being developed and adapted for engine control including crankshaft speed observers, and spark plug ionization and fiber optic detectors. Combustion diagnostics include engine-out $\mathrm{HC}$ and other gaseous emissions measurements. 
Computer modeling, coupled with innovative engine experiments is used to devise strategies for optimizing and controlling HCCI engine performance and reducing emissions over the speed-load range of interest in applications. Engine performance models include zero- and one-dimensional global models for control system development (Task 2). Data for chemical kinetics model validation is obtained using a CFR engine operated on a variety of fuels (Task 4). The influence of turbulence and temperature and mixture inhomogeneities is revealed with highly resolved CFD predictions and laserbased engine experiments (Tasks 5 and 6). (Note that Task 3 was eliminated from the original proposal.)

Results

Task 1: HCCI engine combustion regime mapping - The Caterpillar 3401 engine with an EUI injection system was tested over a wide range of speed and loads. As shown in Fig. 1, low emissions operation could be achieved with late injection timings (i.e., start-ofinjection (SOI) after TDC) up to about $1200 \mathrm{rev} / \mathrm{min}$. At higher engine speeds, particulate matter (PM) levels increased significantly. Figure 1 also shows baseline 6mode steady-state test points of the FTP transient test procedure for reference. It is seen that Premixed Charge Compression Ignition (PCCI) operation was also limited to light load conditions. In PCCI combustion, heat release rate analysis indicates that diffusion burning is minimal, and most of the combustion process occurs in a premixed combustion mode. The engine tests were ranked using a merit function that is based on NOx, PM and BSFC as

$$
\text { Merit }=\frac{1000}{\left(\frac{N O x+H C}{2.682 g / k W-h r}\right)+\left(\frac{P M}{0.107 g / k W-h r}\right)+\frac{B S F C}{200 g / k W-h r}}
$$

where the target values in the denominator reflect EPA 2002/2004 emissions mandates. The corresponding merit values are also indicated on Fig. 1 for each engine test point. Early injection results (i.e., SOI 10-25 degrees before TDC) are shown in Fig. 2. In this case, satisfactory engine operation was achieved for all engine speeds up to $40 \%$ load.

Tasks $1 \&$ 2: Combustion modeling and control - Cylinder pressure, heat release and fuel injection rate data is shown in Fig. 3, together with the merit values for several early injection cases. As can be seen, cases whose start-of-combustion occurs after the injection has ended have the highest merit. The longer time available for mixing in these cases favors premixed-burning, with dramatically reduced PM emissions. KIVA computations of the fuel/air equivalence ratio $(\phi)$ distributions in the engine at the experimental start of combustion times are shown in Figs. 4 and 5 for two early injection cases. Figure 5 shows that with sufficiently early SOI, rich regions $(\phi>2)$ are all but eliminated. This supports the experimental finding that particulate is reduced under these conditions since it is known that PM does not form when $\phi<2$. These results indicate that the ignition delay time after the end of injection may be a suitable parameter for engine control. 
Task 4: Ignition chemistry - A CFR research engine was run in the HCCI combustion mode for a range of temperatures and fuel compositions. The data indicate that the best HCCI operation occurs at or near the rich limit of operation. Analysis of the pressure and heat release histories indicated the presence, or absence, and impact of the fuel's NTC ignition behavior on establishing successful HCCI operation. The auto-ignition trends observed were in complete agreement with previous results found in the literature. Furthermore, analysis of the importance of the fuel's octane sensitivity, through assessment of an octane index, successfully explained the changes in the fuels autoignition tendency with changes in engine operating conditions. For practical HCCI application it will be important to have an optimal phasing of the energy release with the piston motion. If the fuels being used do not have strong NTC behavior, this phasing appears to be most readily obtained through intake temperature control. If the fuel being used exhibits strong NTC behavior the interaction between the in-cylinder temperature, pressure and engine speed becomes significantly more complicated. Under such conditions it seems that some mechanism to trigger the start of HCCI combustion will be needed.

Tasks 5 \&6: Multidimensional Modeling - Work has focused on using 'in-situ adaptive tabulation.' (ISAT) for detailed chemistry in an HCCI application, together with detailed intake flow modeling to understand its impact on HCCI mixture preparation, ignition, and combustion. ISAT potentially reduces the computational time required to simulate complex hydrocarbon oxidation chemistry in HCCI ignition and combustion by automatically tabulating and reusing data. Initial tests for HCCI have shown reduction in computational time by as much as a factor of ten. Part of this was due to a variation on the basic ISAT approach of choosing a subset of parameters to characterize the tabulation. Additional work on CFD modeling has focused on intake flow simulations. These are being used to establish baseline RANS calculations of different intake air temperature and EGR cases before moving to LES models. The initial simulations show good comparison with experimental values of the pressure traces.

\section{Conclusions}

The engine tests have shown that operation at both very early and very late start-ofinjection timings is effective for low emissions. In particular, adequate dwell between the end-of-injection and the start of combustion allows time for fuel/air mixing. Low local equivalence rations are beneficial for particulate reduction and result in HCCI-like combustion. A combustion control criterion based on the ignition/injection time delay is being formulated for low emissions operation. Multidimensional model was applied successfully to help explain the experimental trends for both early and late injection cases. Combustion modeling is in progress, and the fuel chemistry experiments show that HCCI ignition is controlled by effects beyond fuel octane number. This indicates that detailed chemical kinetic models will require further validation by comparison with the present experiments.

FY 2002 Publications/Presentations

DOE HCCI Presentations Meetings: Feb. 19, 2002 and June 11-12, 2002. 


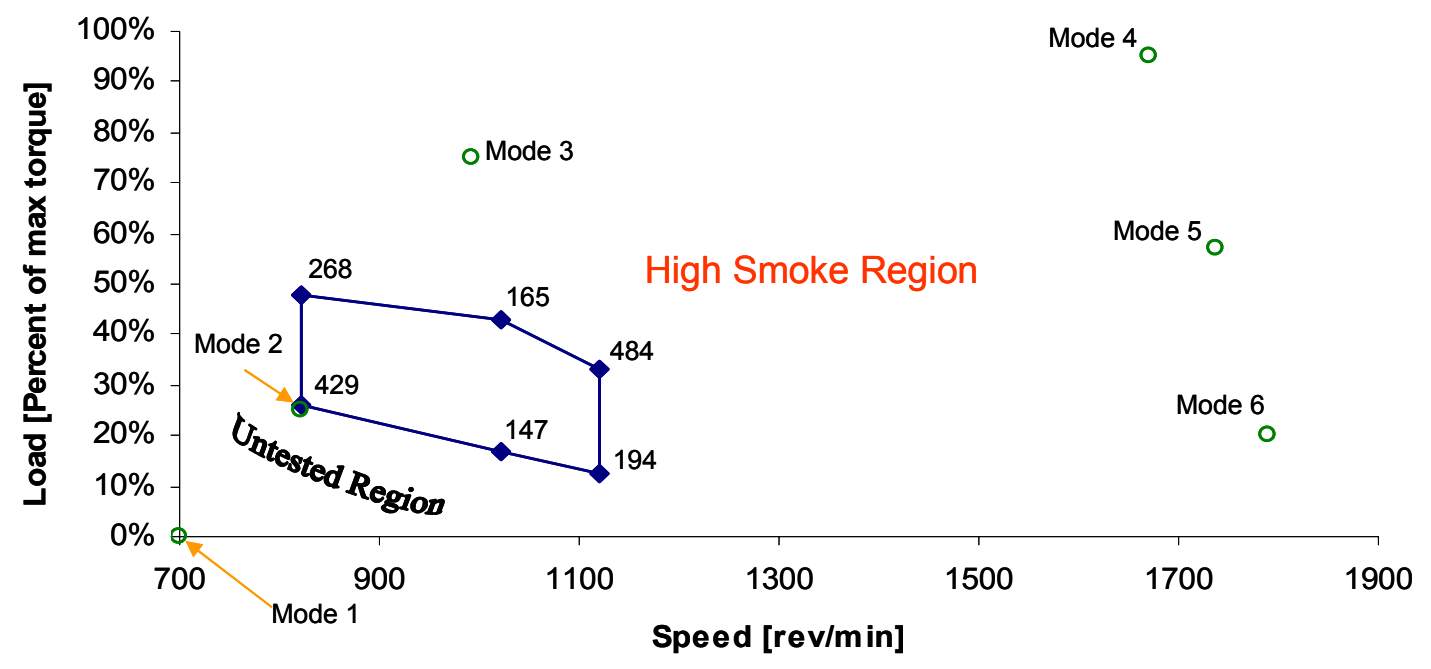

Figure 1 Late start-of-injection operating regime for PCCI combustion

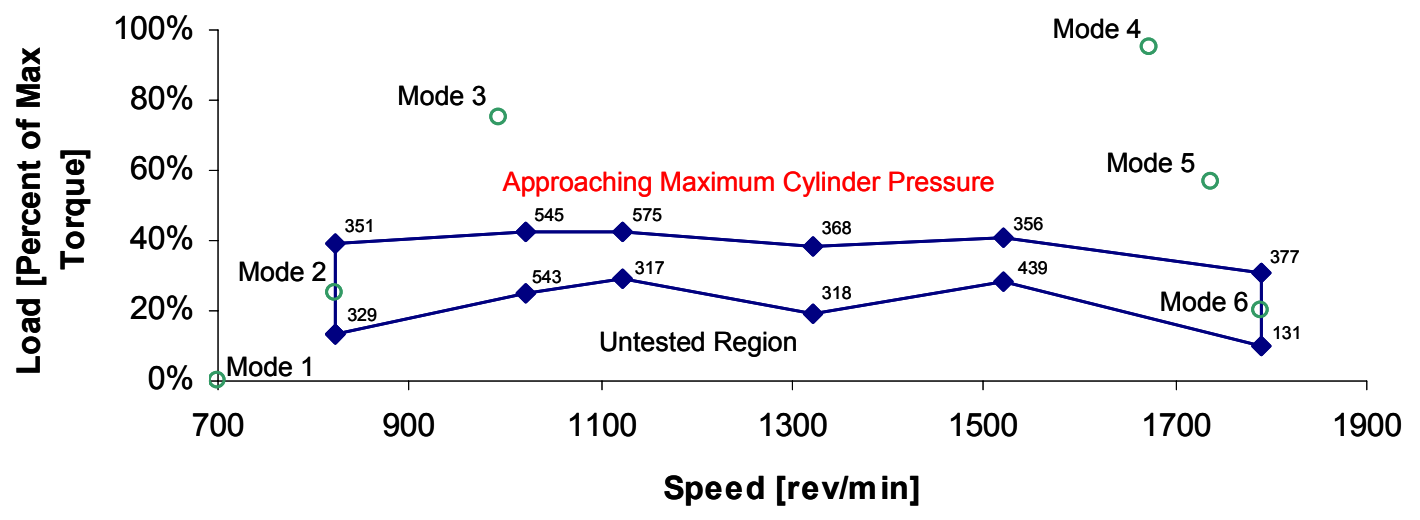

Figure 2 Early start-of-injection operating regime for PCCI combustion 

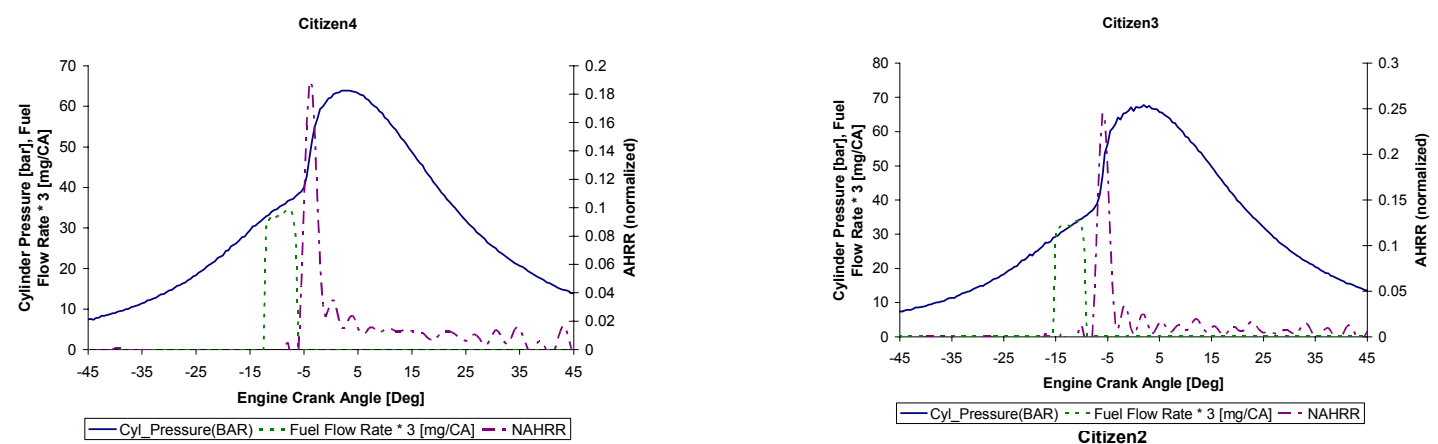

\begin{tabular}{|l|l|l|l|l|}
\hline Citizen & SOI & PM & NOx & Merit \\
\hline 2 & -18 & 0.058 & 0.772 & 592 \\
\hline 3 & -15 & 0.286 & 0.570 & 118 \\
\hline 4 & -12 & 0.717 & 0.457 & 22 \\
\hline
\end{tabular}

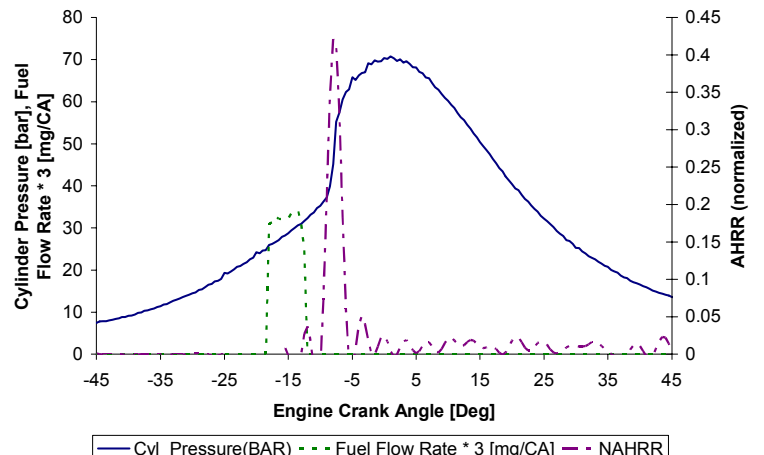

Fig. 3 Measured cylinder pressure, heat release rate and fuel injection rate as a function of start of injection timing for early injection cases

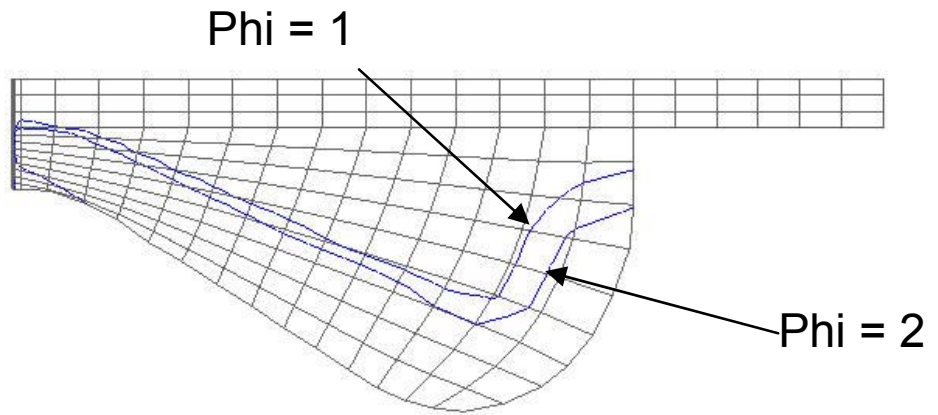

4 deg. after SOI

Fig. 4 Predicted fuel/air equivalence ratio contours for SOI -9 ATDC at the experimental start of combustion time 


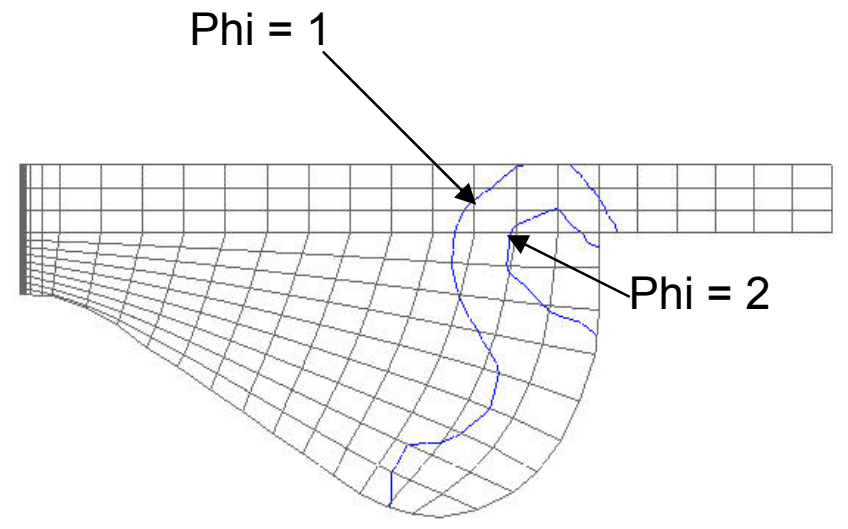

7 deg. after SOI

Fig. 5 Predicted fuel/air equivalence ratio contours for SOI -18 ATDC at the experimental start of combustion time 
APPENDIX B

\title{
2003 Annual Progress Report - Advanced Combustion Engine R\&D Combustion and Emission Control for Advanced CIDI Engines
}

\author{
HCCI Engine Optimization and Control Using Diesel Fuel - R. Reitz, UW \\ Profs. Rolf D. Reitz, Dave Foster, Kevin Hoag and Chris Rutland \\ Engine Research Center \\ University of Wisconsin-Madison \\ 1500 Engineering Drive \\ Madison, WI 53706 \\ Tel: (608) 262-0145, Fax: (608) 262-6707 e-mail: reitz@engr.wisc.edu
}

DOE Program Manager: Gurpreet Singh

Department of Energy, EE 322

1000 Independence Avenue, SW

Washington, DC 20585

Tel: 202-586-2333, Email: gurpreet.singh@hq.doe.gov

Subcontract

Prof. D. Haworth, State College, PA

\section{Objectives}

- Develop methods to optimize and control Homogeneous-Charge Compression Ignition (HCCI) engines, with emphasis on diesel-fueled engines.

- Use engine experiments and detailed modeling to study factors that influence combustion phasing, unburned hydrocarbon (UHC) and $\mathrm{CO}$ emissions.

- Provide criteria for transition to other engine operation regimes (e.g., standard diesel combustion)

\section{Approach}

- Use 2 fully-instrumented engines with prototype fuel injection systems and combustion sensors to map and define HCCI combustion regimes, and apply optimization techniques

- Develop and apply engine performance models, including multi-dimensional, zeroand 1-D global models for control system development

- Use homogeneous and stratified charge CFR engine, and low and high injection pressure heavy-duty engine experiments to document fuel effects on HCCI ignition

- Develop and apply modeling tools, including multi-dimensional codes (e.g., KIVA with state-of-the-art turbulent combustion and detailed and reduced chemistry models) to reveal combustion mechanisms 


\section{Accomplishments}

- Diesel engine operation with high injection pressures at both early and late start-ofinjection timings has been shown to produce low emissions, with HCCI-like combustion. The time between the end of injection and start of combustion has been identified as a useful HCCI control variable.

- Low-pressure diesel fuel injection has been found to lead to significant wall fuel film formation that deteriorates engine performance

- A multidimensional model has been developed and applied successfully to model low and high pressure injection cases

- HCCI engine operating limits have been shown to be extended by operation with stratified combustion

- Detailed combustion computations have been used to identify methodologies to increase mixing prior to ignition for emissions reduction

\section{Future Directions}

- Use of multiple injections for diesel HCCI combustion control will be assessed

- Use of cylinder pressure-based and ion/optical sensing for engine control will be analyzed

- Ignition characteristics of diesel fuel will be explored in engine experiments

- Efficient methods for including detailed kinetics will be implemented and applied in multidimensional models for more accurate combustion predictions

\section{Introduction}

This project is in response to the Department of Energy (DOE) solicitation for research and development on Homogeneous Charge Compression Ignition (HCCI) diesel-fueled engines. Advantages of HCCI operation include significantly reduced NOx and particulate emissions. However, there are significant challenges associated with the successful operation of HCCI engines. One of the major difficulties is to control the combustion phasing - mainly the assurance of auto-ignition at appropriate timings over a wide range of operating conditions. Another obstacle of HCCI engine operation is the relatively high emissions of unburned hydrocarbon (HC) and carbon monoxide (CO) due to incomplete combustion with low-temperature lean burn. The power output of the HCCI engine is also limited since the combustion can become unstable. The present research investigates methods to quantify and overcome these obstacles using a combined experimental and modeling approach.

\section{Approach}

In order to control the engine, it is necessary to know what variables to control. The five (5) technical tasks of the present work provide information about HCCI combustion 
mechanisms for use in knowledge-based engine control schemes. The experiments of Task 1 use a fully instrumented Caterpillar 3401 heavy-duty diesel engine that features electronically controlled fuel injection systems to map combustion regimes. Combustion sensors are being adapted for engine control including acceleration (knock), spark plug ionization and fiber optic detectors. Combustion diagnostics include engine-out $\mathrm{HC}$ and other gaseous emissions measurements. Computer modeling, coupled with innovative engine experiments is also being used to devise strategies for optimizing and controlling HCCI engine performance and reducing emissions over the speed-load range of interest in applications. The engine performance models also include zero- and one-dimensional global models for control system development (Task 2). Data for chemical kinetics model validation is obtained using a CFR engine operated on a variety of fuels (Task 4). The influence of turbulence and temperature and mixture inhomogeneities is revealed with highly resolved CFD predictions (Tasks 5 and 6). (Note that Task 3, In-cylinder Species Measurements, was removed from the original proposal due to funding limitations.)

\section{Results}

Task 1: HCCI engine combustion optimization and regime mapping - The Caterpillar 3401 heavy-duty diesel engine has been tested over a wide range of speed and loads using the stock high-pressure EUI injection system, and the time delay between the end of injection and the start of combustion has been shown to be a potential HCCI control parameter [1]. In the present effort, operation with a commercial GDI low-pressure (10MPa) injector has been studied, including both single and split injections. Poor combustion performance was found at very early and at late injection timings using diesel fuel, however, significantly superior results were found using $n$-heptane. The companion multidimensional computer modeling has revealed that this is due to fuel impingement on the combustion chamber surfaces with the relatively non-volatile diesel fuel, and that minimum impingement occurs with injections close to intake valve closing (-120 deg. ATDC), as shown in Fig. 1. The modeling also shows that at higher boost conditions the spray cone angle is reduced, leading to even more wall impingement. The modeling is being used to suggest optimum injection timings and spray geometries for both high and low injection pressures.

To enhance the computational efficiency of the multi-dimensional models, reduced chemical kinetic mechanisms that consist of limited numbers of species and reactions are being developed. A new reduced mechanism has been generated based on an available $\mathrm{n}$ heptane mechanism (40 species and 165 reactions). The procedure for generating the reduced mechanism includes eliminating unimportant species and reactions, and adjusting kinetic constants in the new mechanism to improve ignition delay predictions. The current reduced mechanism consists of 33 species and 56 reactions and has been validated under both constant-volume and engine conditions. Results of HCCI engine combustion simulations using different reaction mechanisms are shown in Fig. 2. The new reduced mechanism gives cylinder pressure results similar to that of the detailed LLNL mechanism at about 1/10 the computer time. The CPU time of the current reduced 
mechanism is $55 \%$ of that of the base mechanism. Further development and validation of reduced mechanisms is under investigation.

Task 2: Combustion modeling and control - Modeling of a multi-cylinder heavy-duty turbocharged engine has been conducted using a global model to assess the potential of HCCI in applications. As has been documented previously, the HCCI operating regime is limited to moderate engine load due to the high rate of cylinder pressure rise at high loads, and misfire and increased hydrocarbons at low loads. This presents a significant concern for application to on-highway trucks. Figure 3 presents full throttle power at the rear wheels for a $350 \mathrm{HP}$ truck engine. Also shown is the power required for level road operation, and for 1 and $2 \%$ up and down grades. As the vehicle experiences a grade the engine can be operated anywhere underneath and up to the full-throttle curve. As can be seen, at highway speeds even a 1\% uphill grade requires the $350 \mathrm{HP}$ engine to operate at full load. Similarly, slightly more than a $1 \%$ downhill grade results in the engine being motored by the vehicle. Thus, with even slightly hilly terrain the engine will be cycling between no load and full load, with relatively little time spent at the moderate loads most suited for HCCI operation. This suggests that while HCCI may be well suited for passenger car engines, its application to heavy-duty vehicles is problematic. Based on this finding the multi-cylinder engine modeling effort is being focused on light-duty passenger car turbocharged diesel engines.

Task 4: Ignition chemistry - The CFR research engine has been run in the HCCI combustion mode over a wide range of temperatures and fuel compositions, and the effect of fuel composition on the ignition delay has been evaluated [3]. Recent work has been directed at evaluating whether the HCCI operating range can be extended via fuel charge stratification by direct injection of a portion of the fuel into the engine cylinder. The ratio of premixed to direct injected fuel was varied while the overall equivalence ratio was held constant. In addition, the timing of the direct injection of the fuel was also varied. The characterization of optimal HCCI combustion was determined by assessing the coefficient of variation of the IMEP, the maximum rate of pressure rise, the combustion efficiency, emissions and the IMEP. A summary of the results is shown in Fig. 4, which compares the ranges of HCCI operation obtained with homogeneous charge combustion to those obtained with stratified charge operation. In general, stratified charge operation does not offer potential for increasing the rich limit, or the highest load condition. However, stratified charge does provide more stable combustion and an extension of the lean limit, or low load operation. The potential for using stratified charge as a means of expanding, and possibly controlling HCCI operation is being investigated further.

Tasks 5 and 6: Multidimensional Modeling - Advanced combustion models are being developed for HCCI modeling [4]. As suggested from the work of Task 1, an important parameter is the time delay between the end of injection and the start of combustion. It has been shown that with a positive ignition delay, the diffusion burn is diminished and lower temperatures are achieved resulting in less NOx and soot formation [1]. Recent work has focused on understanding parameters including EGR, intake temperature, ignition timing and valve actuation, and their effect on the local equivalence ratio and 
temperature distributions, soot formation and oxidation, intermediate species production/destruction and the variation in chemical and mixing timescales has been observed. Figure 5 shows predicted timescales for an early injection case where combustion begins around -20 deg ATDC. K/E (turbulent kinetic energy/energy dissipation) is indicative of the turbulent (or mixing) timescale, and TAU is the combustion characteristic timescale. These parameters quantify the effect of mixing on the ignition delay and show how the start of combustion is controlled. They are being used to study the impact on the ignition delay of thermal effects (controlled by intake temperature and EGR rates) and mixing effects. This will also be used to study cases where intake valve actuation [2] is used to prolong the ignition delay.

Additional work has focused on the development of storage/retrieval-based chemistryacceleration strategies to accommodate large chemical mechanisms in three-dimensional time-dependent CFD for practical engine configurations. The approach is being extended to stratified reactant mixtures, including direct-injection diesel autoignition using the ISAT method [5] and an improved method [6]. The new algorithm requires considerably less storage (one-to-three orders of magnitude), and yields speedups compared to direct integration even in highly non-homogeneous systems, as shown in Fig. 6.

\section{Conclusions}

The present engine tests have shown that operation at both very early and very late start-of-injection timings is effective for low emissions using high-pressure diesel fuel injection. In particular, adequate dwell between the end-of-injection and the start of combustion allows time for fuel/air mixing. A combustion control criterion based on the ignition/injection time delay has been formulated and is being implemented in a control algorithm for low emissions operation. With low-pressure fuel injection, significant fuel wall impingement occurs and performance deteriorates. Multidimensional modeling has been applied successfully to help explain the experimental trends for both the high and low injection pressure cases. Fuel chemistry experiments show that HCCI ignition is controlled by effects beyond fuel octane or cetane number. This indicates that detailed and reduced chemical kinetic models will require further validation and this is being achieved by comparison with the present engine experiments.

\section{References}

1. Klingbeil, A., "Particulate and NOx Reduction in a Heavy-Duty Diesel Engine Using High Levels of Exhaust Gas Recirculation and Very Early or Very Late Start of Injection," MS Thesis, University of Wisconsin-Madison, 2002.

2. Reitz, R.D., Rutland, C.J., and Jhavar, R., "Controlled Valve Actuation for Emissions Reduction," University of Wisconsin Alumni Research Foundation (WARF) Patent Application Ref. No. P03152US/09820263, January, 2003. 
3. Aroonsrisopon, T., Sohm, V., Werner, P., Foster, D.E., Morikawa, T., and Iida, M., "An Investigation Into the Effect of Fuel Composition on HCCI Combustion Characteristics", SAE Paper 2002-01-2830, 2002.

4. Rao, S., Rutland, C.J., and Fiveland, S.B., “A Computationally Efficient Method for the Solution of Methane - Air Chemical Kinetics with Application to HCCI Combustion," SAE Paper 2003-01-1093, 2003.

5. S.B. Pope, "Computationally efficient implementation of combustion chemistry using in situ adaptive tabulation," Combust. Theory \& Modelling 1:41-63 (1997).

6. Veljkovic, P.E. Plassmann and D.C. Haworth, "A scientific on-line database for efficient function approximation," 2003 International Conference on Computational Science, Saint Petersburg, Russian Federation and Melbourne, Australia (2-4 June 2003).

\section{FY 2003 Publications/Presentations}

1. DOE HCCI Presentations Meetings: January 30, 2003 (Sandia) and June 26, 2003 (USCAR).

2. Kong, S.-C., and Reitz, R.D., "Application of Detailed Chemistry and CFD for Predicting Direct Injection HCCI Engine Combustion and Emissions" Proceedings 29th International Symposium on Combustion, July 21-26, 2002.

3. Ricklin, P.U., Kazakov, A., Dryer, F.L., Kong, S.-C., and Reitz, R.D., "The Effects of NOx Addition on the Auto Ignition Behavior of Natural Gas under HCCI Conditions," SAE paper 2002-01-1746, 2002.

4. Kong, S.,-C., Reitz, R.D., Christensen, M., and Johansson, B., "Modeling the Effects of Geometry Generated Flow Turbulence on HCCI Combustion," SAE paper 2003-011088, 2003.

5. Canakci, M., and Reitz, R.D., "Experimental Optimization of a DI-HCCI-Gasoline Engine Using Split Injections with Fully-Automated Micro-Genetic Algorithms," International Journal of Engine Research, Vol. 4, No. 1, pp. 47-60, 2003. 6. Canakci, M., and Reitz, R.D., "Experimental Optimization of a DI-HCCI-Gasoline Engine's Performance and Emissions Using Split Injections with Fully-Automated Micro-Genetic Algorithms," Accepted for publication, ASME Journal of Gas Turbines and Power, March, 2002.

7. Rao, S., Rutland, C.J., and Fiveland, S.B., "A Computationally Efficient Method for the Solution of Methane - Air Chemical Kinetics with Application to HCCI Combustion," SAE Paper 2003-01-1093, 2003.

8. Aroonsrisopon, T., Sohm, V., Werner, P., Foster, D.E., Morikawa, T., and Iida, M., "An Investigation Into the Effect of Fuel Composition on HCCI Combustion Characteristics", SAE Paper 2002-01-2830, 2002.

9. Veljkovic, P.E. Plassmann and D.C. Haworth, "A scientific on-line database for efficient function approximation," 2003 International Conference on Computational Science, Saint Petersburg, Russian Federation and Melbourne, Australia (2-4 June 2003).

10. D.C. Haworth, "Multidimensional modeling of combustion in homogeneous-charge compression-ignition (HCCI) engines using storage/retrieval-based chemistry," (with L. 
Wang, E. Kung, I. Veljkovic, P.E. Plassmann and M. Embouazza), invited speaker, Department of Mechanical Engineering, University of Pittsburgh, Pittsburgh, PA (28 February 2003); also Centre Européen de Recherche et de Formation Avancée en Calcul Scientifique, Toulouse, France (19 March 2003).

11. D.C. Haworth, L. Wang, E. Kung, I. Veljkovic, P.E. Plassmann and M. Embouazza "Detailed chemical kinetics in multidimensional CFD using storage/retrieval algorithms," $13^{\text {th }}$ International Multidimensional Engine Modeling Users' Group Meeting, Detroit, MI (2 March 2003).

12. D.C. Haworth, "Applications of turbulent combustion modeling," in Turbulent Combustion, (J.P.A.J. Van Beeck, L. Vervisch and D. Veynante, Eds.), von Karman Institute for Fluid Dynamics Lecture Series, Rhode-Saint-Genèse, Belgium, 17-21 March, to appear (2003).

13 M. Iida, M. Hayashi, D. Foster, J. Martin, "Characteristics of Homogeneous Charge Compression Ignition (HCCI) Engine Operation for Variation in Compression Ratio, Speed, and Intake Temperature While Using n-Butane as a Fuel" Journal of Engineering for Gas Turbines ans Power, ASME, April 2003, Vol 125.

\section{Special Recognitions \& Awards/Patents Issued}

R.D. Reitz, C.J. Rutland and R. Jhavar, "Controlled Valve Actuation for Emissions Reduction," University of Wisconsin Alumni Research Foundation (WARF) Patent Application Ref. No. P03152US/09820263, January, 2003.

\section{Acronyms}

ATDC After Top Dead Center of compression

CFD Computaional Fluid Dynamics

CFR Cooperative Fuels Research

CPU Central Processing Unit

CR Compression Ratio

CU Chalmers University

DI Direct Injection

ERC Engine Research Center

EUI Electronic Unit Injector

GDI Gasoline Direct Injection

HCCI Homogeneous Charge Compression Ignition

IMEP Indicated Mean Effective Pressure

ISAT In Situ Adaptive Tabulation

LLNL Lawrence Livermore National Labs

PRF Primary Reference Fuel 


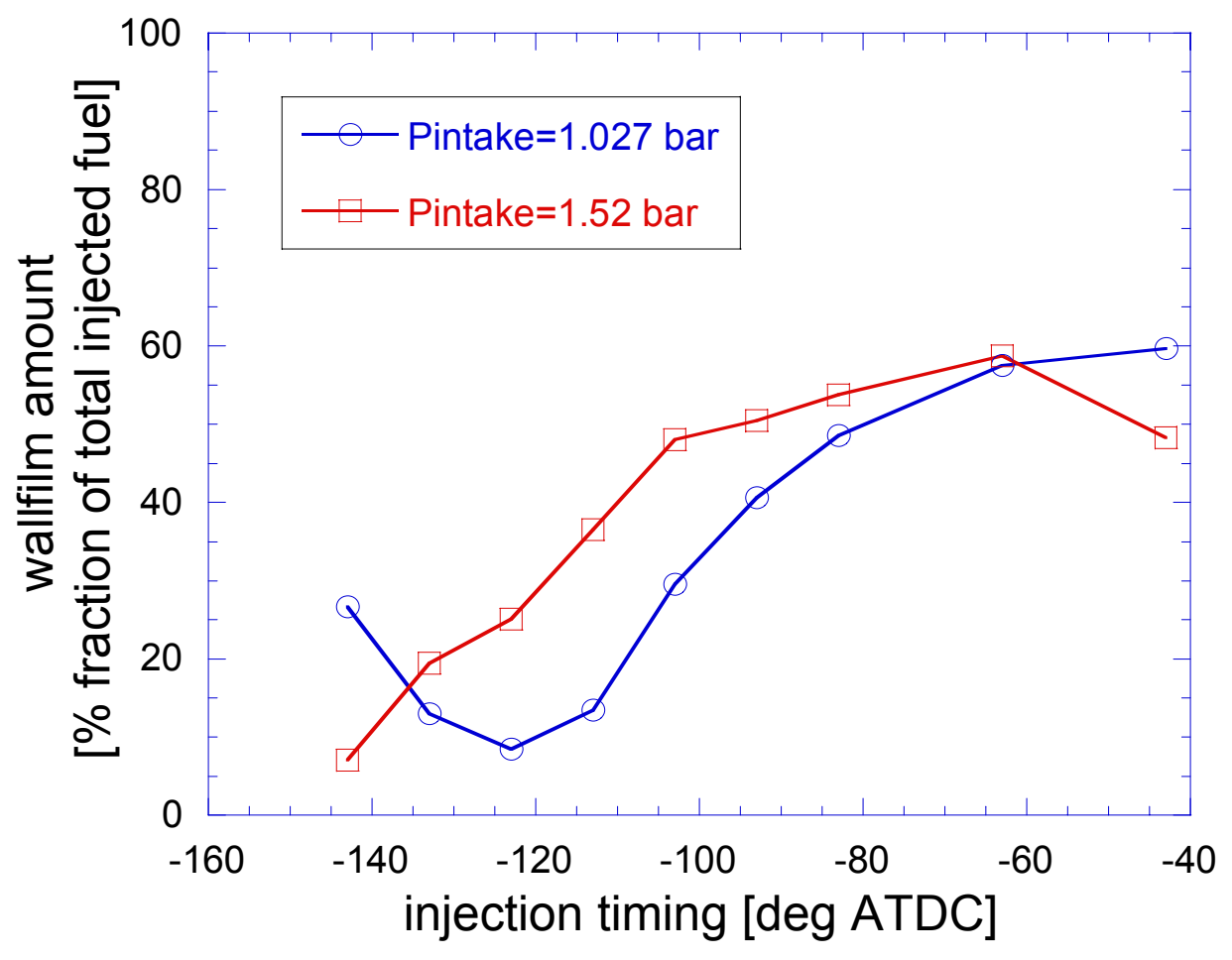

Figure 1. Predicted amount of fuel impinged on combustion chamber surfaces with diesel fuel as a function of the start-of-injection timing using low-pressure GDI injector for naturally aspirated and boosted operation.

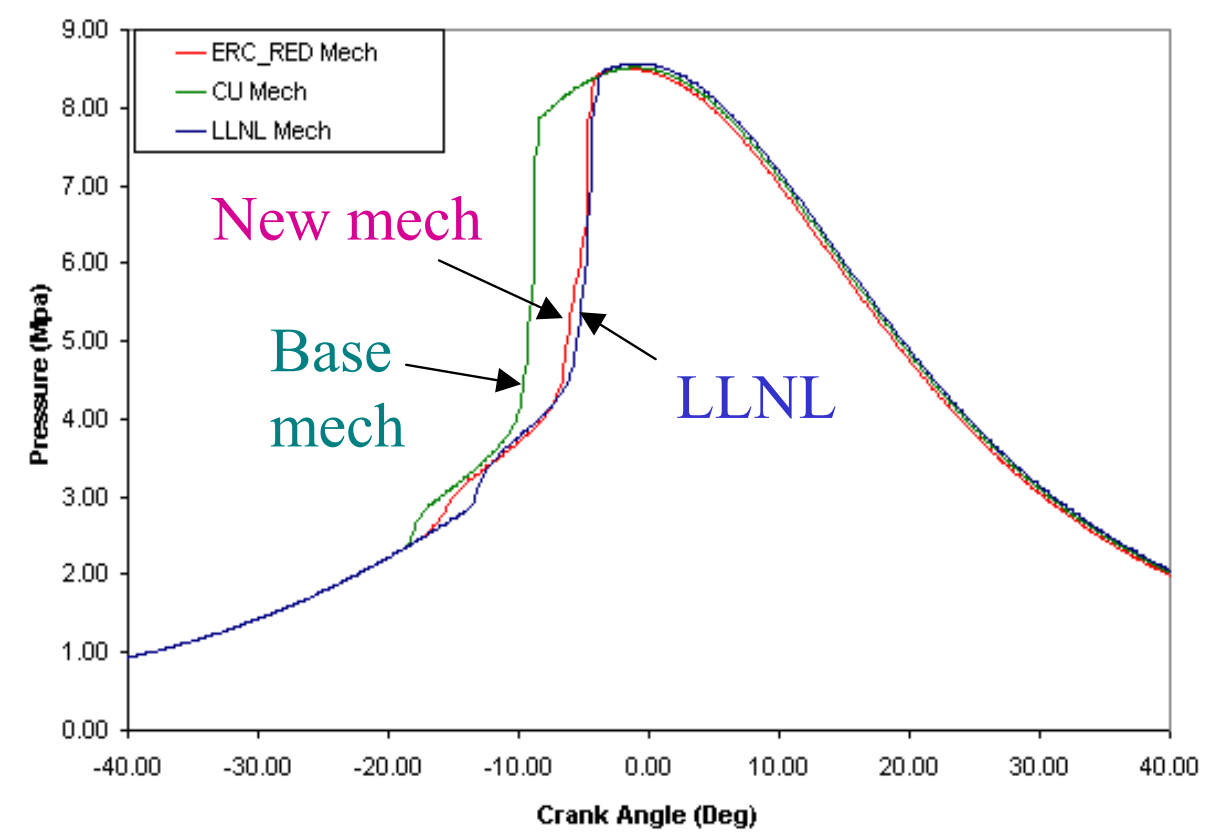

Figure 2. Predicted cylinder pressure for early injection using the new (ERC) reduced chemistry, baseline (CU) and detailed (LLNL) mechanisms 


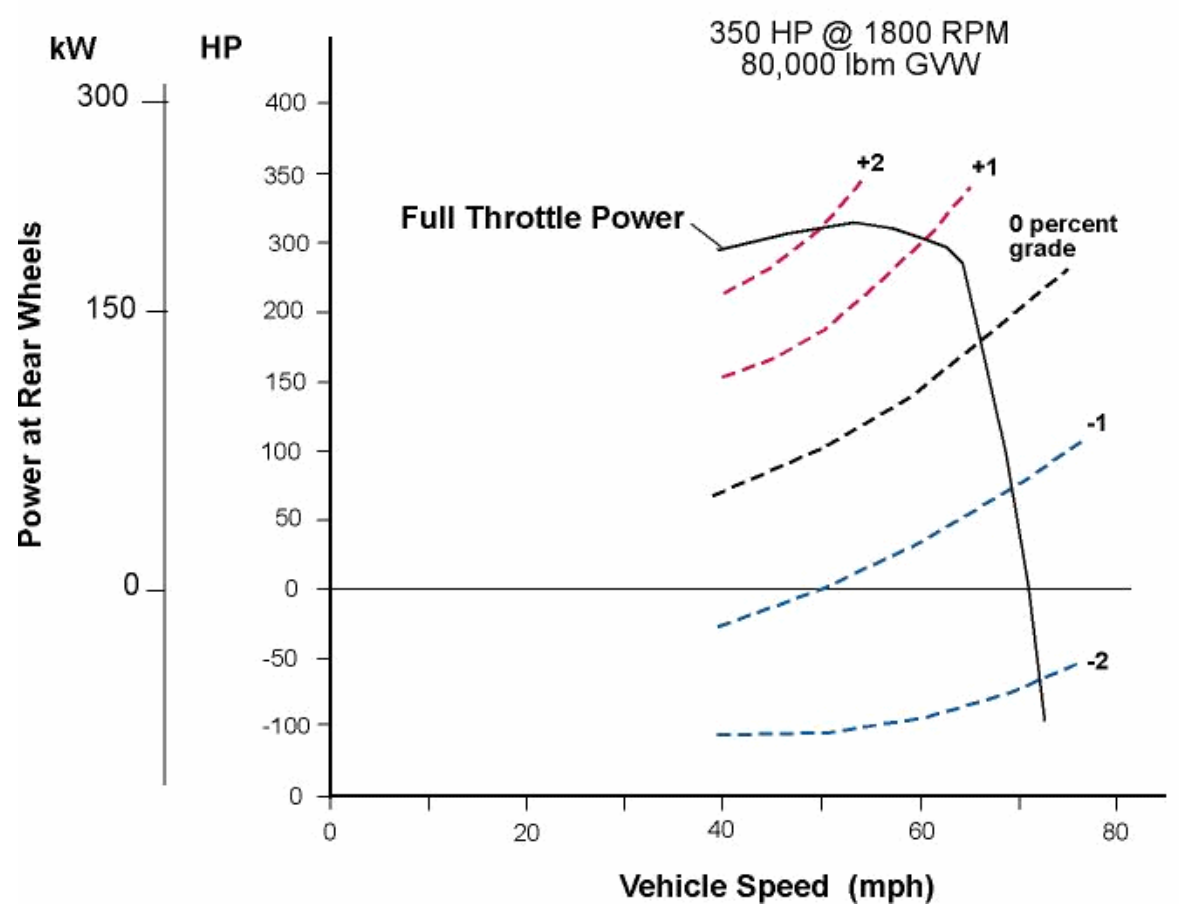

Figure 3. Heavy duty truck power requirements as a function of grade level and speed.
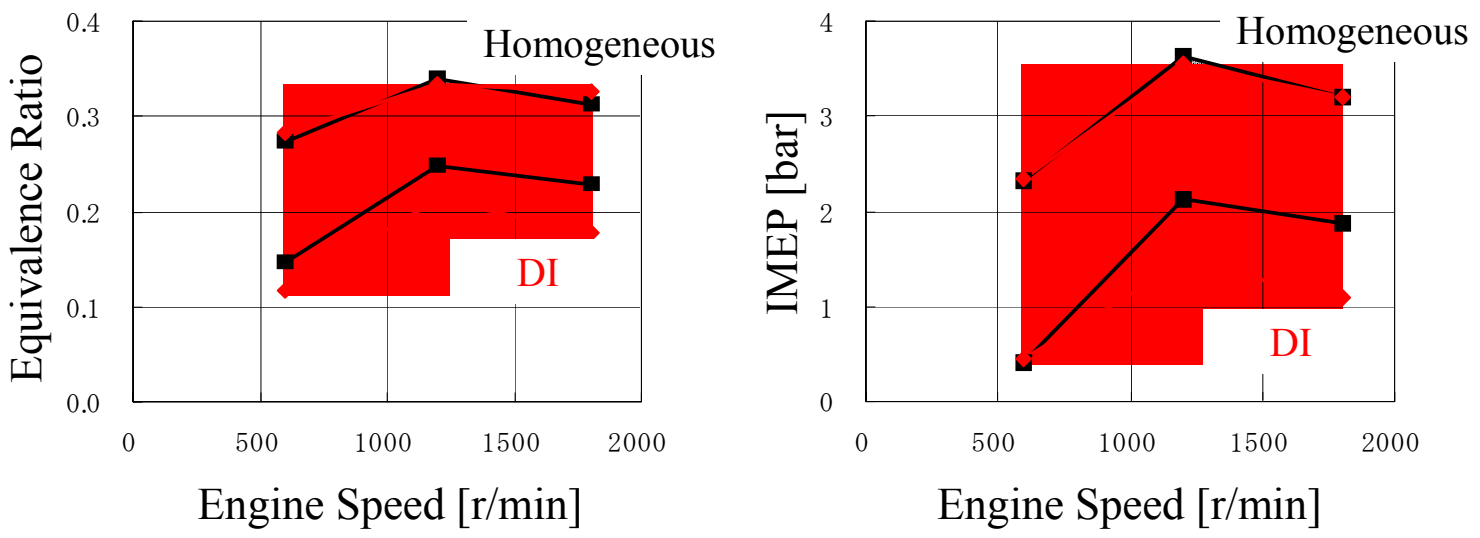

Figure 4. HCCI operating ranges for complete homogeneous charge mixtures and the optimum combination of premixed and direct injected fuel. $\mathrm{CR}=16.55$, Fuel $=$ PRF 92, Tintake $=107^{\circ} \mathrm{C}$. 


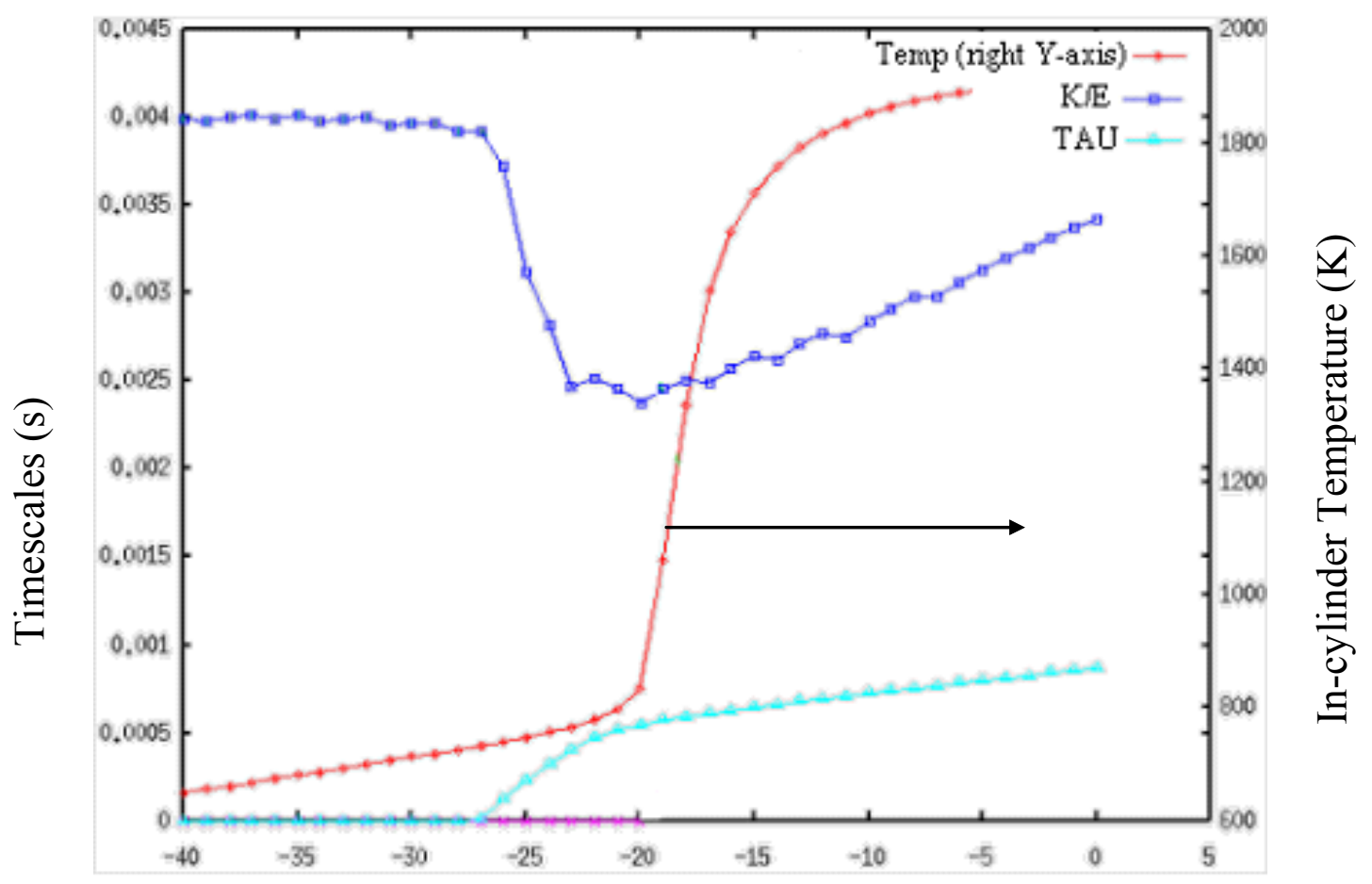

Crank Angle (ATDC)

Figure 5. Variation of turbulence (K/E) and combustion (TAU) timescales with temperature for an early injection diesel $\mathrm{HCCI}$ engine case

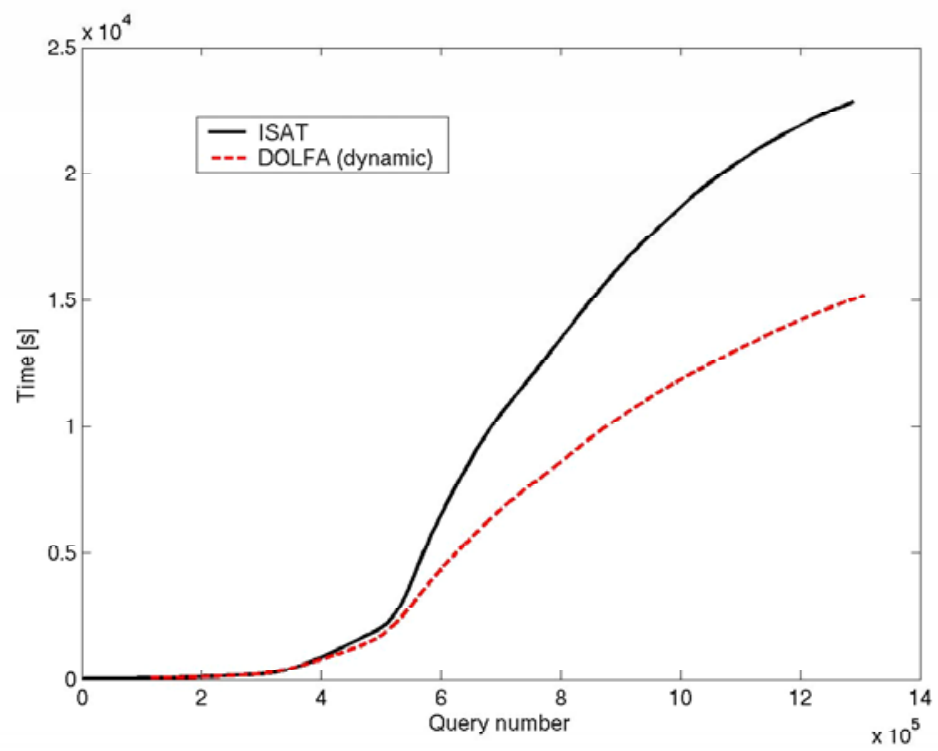

Figure 6. Cumulative CPU time for a direct-injection autoignition case using ISAT [5] and the new storage/retrieval scheme [6]. 


\title{
APPENDIX C
}

\section{Annual Progress Report - Advanced Combustion Engine R\&D Combustion and Emission Control for Advanced CIDI Engines}

\author{
HCCI Engine Optimization and Control Using Diesel Fuel - R. Reitz, UW
}

Profs. Rolf D. Reitz, Dave Foster, Jaal Ghandhi, Kevin Hoag and Chris Rutland Engine Research Center

University of Wisconsin-Madison

1500 Engineering Drive

Madison, WI 53706

Tel: (608) 262-0145, Fax: (608) 262-6707 e-mail: reitz@engr.wisc.edu

DOE Program Manager: Gurpreet Singh and Kevin Stork

Department of Energy, EE 322

1000 Independence Avenue, SW

Washington, DC 20585

Tel: 202-586-2333, Email: gurpreet.singh@hq.doe.gov and kevin.stork@ee.doe.gov

Subcontract

Prof. D. Haworth, State College, PA

\section{Objectives}

- Develop methods to optimize and control Homogeneous-Charge Compression Ignition (HCCI) engines, with emphasis on diesel-fueled engines.

- Use engine experiments and detailed modeling to study factors that influence combustion phasing, unburned hydrocarbon (UHC) and $\mathrm{CO}$ emissions.

- Provide criteria for transition to other engine operation regimes (e.g., standard diesel and low temperature combustion)

\section{Approach}

- Use 2 fully-instrumented engines with prototype fuel injection systems and combustion sensors to map and define HCCI combustion regimes, and apply optimization techniques

- Develop and apply engine performance models, including multi-dimensional, zeroand 1-D global models for control system development

- Use homogeneous and stratified charge CFR engine, and low and high injection pressure heavy-duty engine experiments to document fuel effects on HCCI ignition

- Develop and apply modeling tools, including multi-dimensional codes (e.g., KIVA with state-of-the-art turbulent combustion and detailed and reduced chemistry models) to reveal combustion mechanisms 


\section{Accomplishments}

- Diesel HCCI combustion regimes have been identified on a Caterpillar 3401 engine using both low pressure (GDI) and high pressure multiple injection strategies

- Evaluated and selected combustion sensors and methodologies for engine control

- Low-pressure diesel fuel injection has been shown to lead to significant wall fuel film formation that deteriorates engine performance

- Models used to propose methods to minimize wall film fuel and to provide start-ofcombustion control via variable valve timing and variable geometry sprays

- HCCI engine operating limits have been shown to be extended by operation with stratified combustion

- Detailed combustion computations have been used to identify methodologies to increase mixing prior to ignition for emissions reduction

\section{Future Directions}

- Use of multiple injections for diesel HCCI combustion control will be assessed

- Guidelines for diesel HCCI will be obtained by experiments and modeling using variable intake valve actuation for combustion phasing control

- Diesel HCCI will be investigated using fumigated/DI with port injection and highpressure diesel injection systems

- Efficient methods for including detailed kinetics will be implemented and applied in multidimensional models for more accurate combustion predictions

\section{Introduction}

This project is in response to the Department of Energy (DOE) solicitation for research and development on Homogeneous Charge Compression Ignition (HCCI) diesel-fueled engines. Advantages of HCCI operation include significantly reduced NOx and particulate emissions. However, there are significant challenges associated with the successful operation of HCCI engines. One of the major difficulties is to control the combustion phasing - mainly the assurance of auto-ignition at appropriate timings over a wide range of operating conditions. Another obstacle specific to diesel HCCI engine operation is the fact that the early injection required to provide time for fuel-air mixing can lead to wall impingement and, consequently, poor combustion efficiency. In addition, the formation of relatively high emissions of unburned hydrocarbon (HC) and carbon monoxide (CO) can occur due to incomplete combustion with low-temperature lean burn. The power output of the HCCI engine is also limited since the combustion can become unstable. The present research investigates methods to quantify and overcome these obstacles using a combined experimental and modeling approach. 


\section{Approach}

In order to control the engine, it is necessary to know what variables to control. The six (6) technical tasks of the present work provide information about HCCI combustion mechanisms for use in knowledge-based engine control schemes. The experiments of Task 1 use a fully instrumented Caterpillar 3401 heavy-duty diesel engine that features electronically controlled fuel injection systems to map combustion regimes. Combustion sensors have been investigated for engine control, including acceleration (knock), ionization and cylinder-pressure detectors. Combustion diagnostics include engine-out particulate, NOx, HC and other gaseous emissions measurements. Computer modeling, coupled with the engine experiments is also being used to devise strategies for optimizing and controlling HCCI engine performance and reducing emissions over the speed-load range of interest in applications. The engine performance models include zero- and onedimensional global models for control system development (Task 2). Task 3, In-cylinder Measurements (removed from the original proposal due to funding limitations, but now included with matching funding from industry) provides detailed validation data for chemical kinetics models. Additional model validation data is obtained using a CFR engine operated with various fuels (Task 4). The influence of turbulence, temperature and mixture inhomogeneity is revealed with highly resolved CFD predictions (Tasks 5 and 6).

\section{Results}

Task 1: HCCI engine combustion optimization and regime mapping - The Caterpillar 3401 heavy-duty diesel engine has been tested over a wide range of speed and loads using low and high pressure injection systems and various injection strategies [1]. It was found that to achieve highly premixed combustion (HCCI-like) conditions, optimal dwell between the end of injection and the start of combustion is required to allow sufficient time for fuel-air mixing. The local mixture must be lean for soot/NOx control [2]. With early injections (e.g., 50 degrees btdc), wall wetting is a significant problem. With highpressure injection, an injection time earlier than $30 \mathrm{deg}$. btdc can cause unacceptably high rates of pressure rise, or lead to significant lost fuel due to wall impingement. On the other hand, combustion stability becomes a problem if the fuel is injected late in the cycle (e.g., after $20 \mathrm{deg}$. atdc). With low-pressure injection, the combustion process is complicated by a compromise between vaporization, mixing and ignition that is especially severe with the use of diesel fuel [3,4]. A real-time control methodology based on a RSM technique has been established that uses a cylinder pressure sensor for feedback control. The methodology has been applied to optimize high injection pressure engine operation using a multiple injection strategy [5].

Detailed chemistry models have been developed using an efficient skeletal reaction mechanism to describe diesel fuel oxidation chemistry $[6,7,8]$. NOx and soot emission models have been integrated into the mechanism such that the model successfully predicts the combustion process, as well as emissions trends. Acetylene is used as the 
soot formation species in the model formulation. Application of the model has shown that low soot emissions at early start-of-injection (SOI) timings (e.g., 20 btdc) is due to enhanced oxidation, while low soot emissions at late SOI (e.g., 5 atdc) is a result of less soot formation. The model is being further used to study combustion phasing control using variable IVC timing that has the same effects as varying the compression ratio [9]. Effects of load, boost and engine speed have been investigated, and the results have shown that the $50 \%$ burn point is retarded at high engine speed due to the shorter times available for chemical reactions. Combustion phasing can be optimized by increasing the engine load such that the IVC is within a controllable range, as shown in Fig. 1. In addition, it is found that $50 \%$ burn point is largely unaffected by boost, which can be used at higher loads to improve IMEP. The present CFD models have also been used to explore the benefits of using variable geometry sprays (VGS) on mixture preparation for low-pressure injection DI HCCI operation. The results show that the amount of wall film fuel van be drastically reduced if the included spray angle is allowed to vary from a smaller angle at the beginning to a wider angle at the end of injection, as shown in Fig. 2 [10]. Future modeling study will include the optimization of intake valve timing with the VGS multiple injection strategy and EGR. Models will also be used to help set up experimental PFI-DI conditions to explore diesel HCCI low-emission operation.

Task 2: Combustion modeling and control - Cycle simulation models are an important tool in understanding and developing viable combustion systems for HCCI operation. However, currently available cycle simulation codes lack advanced models for HCCI combustion. Under this project, advanced system level modeling tools are being developed that can accurately predict direct injection diesel fueled HCCI combustion. These are incorporated into control systems to study the basic time scales and feasibility of various control strategies during transient operations.

Commercially available full cycle simulation codes are a convenient starting point as they readily model gas exchange process. Three different approaches were used to couple advanced models with a cycle simulation program to capture the physics of HCCI combustion. The coupled simulations are used to study basic combustion controllers, and to analyze fundamental aspects of speed/load transients in DI diesel HCCI operation. In the first approach, the GT-Power engine simulation code, was integrated with Chemkin as a single zone external combustion model to facilitate detailed chemistry calculations. In the second approach an external cylinder model was developed and implemented into GT-Power. This model incorporates sub-models for fuel injection, vaporization, detailed chemistry calculations (Chemkin), heat transfer, and energy and species conservation. To improve the modeling accuracy, a multi-zone approach was used to account for temperature and fuel stratifications in the cylinder charge [11]. In the third approach, the multi-dimensional ERC-KIVA CFD code was coupled with GT-Power. The primary motivation for this coupling was to more accurately model the fuel injection process since it is critical in DI HCCI operation. To reduce run times, a validated coarse grid version of ERC-KIVA is being used.

The simulation results have been validated with experimental data from the Caterpillar 3401 engine modified for DI diesel HCCI operation. Parametric studies were conducted 
to identify the variables affecting ignition timing and the coupled simulation was used to demonstrate transient operations in speed and load to develop closed loop control strategies, as shown in Fig. 3. This example shows that a fuel savings of up to $3 \%$ are predicted with optimal control of fuel injection and intake valve closure timings. Future work aims at continued model development to make the system level tools faster and more accurate, better understanding of the physics and relevant times scales for combustion control, and evaluation of relative advantages and disadvantages of various control concepts.

Task 3: In-cylinder Measurements - Near-wall planar measurements are being pursued in order to investigate the role of thermal stratification due to the cold cylinder walls. The experiment, however, cannot be performed in the manner of most planar laser-based measurements due to vignetting. (Vignetting is an optical effect that arises when an extended obstruction (e.g., the combustion chamber surfaces) is between the camera and the image plane resulting in a reduction of the signal intensity near the obstruction, which is where one desires quantitative intensity information.) To overcome this problem, a through-the-wall illumination technique is being developed. Line-of-sight absorption measurements are being pursued to quantitatively measure the $\mathrm{OH}$ concentration as a function of temperature near the lean combustion limit. Presently, the design of the optical system is being undertaken. Finally, a modeless, wavelength-agile laser source has been developed to measure $\mathrm{H}_{2} \mathrm{O}$ concentration and temperature. Measurements over a wide range of operating conditions will be pursued next. Wavelength-agile sources that will allow the measurement of other species are also being pursued.

Task 4: Ignition chemistry - A focus of the research has been experimental engine tests on charge stratification as a means of extending the light load operating range. The results show that there are operating windows at light load conditions in which HCCI operation is improved via charge stratification [12]. Under these conditions if the charge is premixed the combustion quality is poor and the $\mathrm{CO}$ and $\mathrm{HC}$ emissions are very high. As the degree of stratification is increased, the $\mathrm{CO}$ and $\mathrm{HC}$ can be reduced. However, as the stratification is increased further, NOx starts to increase.

A companion CFD modeling effort has attempted to quantify the threshold stratification for which combustion is improved, yet NOx stays low. These simulations were conducted as full 3-D calculations that included the intake process, and sample results are shown in Fig. 4. Five operating conditions have been simulated, at $600 \mathrm{rev} / \mathrm{min}$, compression ratio 16.6 , equivalence ratio 0.15 , with iso-octane as the fuel used in the simulation (the data are for PRF 91.8, the fuel that enabled us to explore the stratified operating conditions). Except for the premixed homogeneous case all the fuel was directly injected into the cylinder. The injection profile for each case was created based on a validated spray model.

The trend of NOx versus time of start of injection (SOI) is shown across the bottom of Fig. 4. It is observed that the NOx stays low when start of injection occurs earlier than $90^{\circ}$ btdc. Also, it was noted that there is significant stratification in both equivalence ratio and temperature right up to start of combustion for all cases investigated, even those 
in which the NOx emission from the cylinder is low (see Fig. 4). However, when NOx increases as injection timing is retarded, it increases very rapidly.

Tasks 5 and 6: Multidimensional Modeling - The impact of mixing and fuel preparation on HCCI combustion phasing, specifically the study of ignition 'dwell' between end of fuel injection and start of combustion, are being studied using CFD. Temperature is known to have a large and direct impact on the timing and duration of ignition dwell. However, initial fuel-air distribution and mixing can also affect combustion phasing, with the advantage of a much faster response time than changes in temperature. To investigate the impact of mixing, variations in EGR \%, fuel injection timing, engine valve actuation and swirl ratio magnitude were simulated. To determine the extent for fuel-air mixing generated by these techniques, the equivalence ratio and temperature distribution, intermediate radical formation, mixing timescales and fuel vaporization were analyzed. The results showed that the initial fuel-air distribution did affect the ignition dwell, although to a smaller extent than changes in temperature [12].

Currently work is in progress to incorporate several Large Eddy Simulation (LES) models into the study. LES models are more accurate in depicting the large scale fluid flow structures and will help understand details of mixing in the engine. Figure 5 shows a sample result using the standard Smagorinsky LES model. This image was used to study the details of the flow structure and temperature profiles during the intake stroke. These profiles were compared with earlier profiles from RANS models. It was observed that the LES profiles were able to capture important details of the flow structure. For example, in the top image, eddies are observed downstream of the valve stems in the intake manifold. These are caused by reverse flow at the beginning of the intake stroke and they result in the induction of cooler air into the cylinder later during the intake stroke. This affects the in-cylinder temperature and charge mass so that the LES predictions show a better match with experimental results.

Consistent hybrid particle/finite-volume probability density function (PDF) methods [13], detailed chemical kinetics [14, 15], and chemistry acceleration strategies $[8,16]$ have been also developed for three-dimensional time-dependent simulations of autoignition and emissions in HCCI engines. The resulting model has been compared with experimental measurements in the CFR engine [17, 18], as shown in Figure 6. With no explicit tuning to match these experiments, the model captures the trends with variations in equivalence ratio and other operating conditions.

The influence of turbulence/chemistry interactions (TCI) on autoignition and emissions (CO and unburned hydrocarbons) has been examined by considering the joint PDF of up to 40 chemical species and mixture enthalpy. Variations in global equivalence ratio, wall temperature, swirl level, degree of mixture inhomogeneity (including direct in-cylinder fuel injection), and a top-ring-land crevice (TRLC) have been investigated and sensitivities to model parameters and engine operating conditions have been established $[19,20]$. Key findings are that, for nearly homogeneous reactants with low to moderate swirl and no TRLC, TCI has little effect on ignition timing. However, even in that case the influence of TCI on emissions is not negligible. In addition, with increasing levels of 
swirl, higher degrees of mixture inhomogeneity, and for cases that include a TRLC, TCI effects become increasingly important and result in significant changes in ignition timing, global in-cylinder temperature and pressure, and emissions. Finally, unburned fuel is a non-negligible contribution to UHC only in cases with high swirl or where a TRLC has been considered.

\section{Conclusions}

The engine tests have shown that operation at both very early and very late start-ofinjection timings is effective for low emissions using high-pressure diesel fuel injection. A combustion control criterion based on the ignition/injection time delay has been formulated and has been implemented in a control algorithm for low emissions operation. With low-pressure fuel injection, and early injection for mixing significant fuel wall impingement occurs and performance deteriorates. Multidimensional modeling has been applied successfully to provide guidelines to minimize wall fuel using variable geometry sprays. In addition, variable intake valve closure timing has been shown to be useful for combustion phasing control in diesel HCCI. Detailed turbulence and chemistry models have been developed and are being applied to study mixing and combustion in diesel HCCI engines. It is concluded that PDF methods are a practical and valuable approach for three-dimensional time-dependent modeling of HCCI autoignition and emissions.

\section{References}

1. Klingbeil, Adam, "Particulate and NOx Reduction in a Heavy-Duty Diesel Engine Using High Levels of Exhaust Gas Recirculation and Very Early or Very Late Start of Injection," MS Thesis, University of Wisconsin-Madison, 2002.

2. Klingbeil, A.E., Juneja, H., Ra, Y. and Reitz, R.D., "Premixed Diesel Combustion Analysis in a Heavy-Duty Diesel Engine," SAE paper 2003-01-0341, 2003.

3. Canakci, M., and Reitz, R.D., "Experimental Optimization of a DI-HCCI-Gasoline Engine Using Split Injections with Fully-Automated Micro-Genetic Algorithms," International Journal of Engine Research, Vol. 4, No. 1, pp. 47-60, 2003.

4. Canakci, M., and Reitz, R.D., "Experimental Optimization of a DI-HCCI-Gasoline Engine's Performance and Emissions Using Split Injections with Fully-Automated Micro-Genetic Algorithms," ASME Journal of Gas Turbines and Power, Vol. 126, No. 1, pp. 167-177, 2004.

5. Von Der Ehe, J., "Closed-Loop Feedback Control of a Heavy-Duty Diesel Engine for Emissions Reduction.“ MS Thesis, University of Wisconsin-Madison, 2004.

6. Kong, S.-C., and Reitz, R.D., "Use of Detailed Chemical Kinetics to Study HCCI Engine Combustion with Consideration of Turbulent Mixing Effects," ASME Journal of Gas Turbines and Power, Vol. 124 (3), pp. 702-707, 2002.

7. Kong, S.,-C., Patel, A., Yin, Q., Klingbeil, A., and Reitz, R.D., "Numerical Modeling of Diesel Engine Combustion and Emissions Under HCCI-Like Conditions with High EGR Levels," SAE paper 2003-01-1087, 2003. 
8. Patel, A., Kong, S.-C., and Reitz, R.D., "Development and Validation of a Reduced Reaction Mechanism for HCCI Engine Simulations," SAE Paper 2004-01-0558, 2004.

9. Munnannur, A., Kong, S.-C., and Reitz, R.D., "Performance Optimization of Diesel Engines with Variable Intake Valve Timing via Genetic Algorithms," Submitted to 2005 SAE Congress, September, 2004.

10. Ra, Y., and Reitz, R.D., "The Use of Variable Geometry Sprays with Low Pressure Injection for Optimization of Diesel HCCI Engine Combustion," Submitted to 2005 SAE Congress, October, 2004.

11. Narayanaswamy, K. and Rutland, C. J., "Cycle Simulation Diesel HCCI Modeling Studies and Control," SAE Paper No. 2004-01-2997 (To appear SAE Powertrain Conference, Tampa, FL, Oct 25-28, 2004)

12. Aroonsrisopon, T., Sohm, V., Werner, P., Foster, D.E., Morikawa, T., and Iida, M., "An Investigation Into the Effect of Fuel Composition on HCCI Combustion Characteristics", SAE Paper 2002-01-2830, 2002.

13. Jhavar R., Rutland C.J., "A Computational Study of the Impact of Mixing on HCCI", Proceedings of THIESEL 2004, Universidad Politecnica De Valencia, Spain, September 2004.

14. Zhang, Y.Z., and D.C. Haworth, "A general mass consistency algorithm for hybrid particle/finite-volume PDF method," J. Comput. Phys. 194:156-193 (2004).

15. Nordin, N., "Numerical Simulation of Non-Steady Spray Combustion Using a Detailed Chemistry Approach," Thesis for the degree of Licenciate of Engineering, Department of Thermo and Fluid Dynamics, Chalmers University of Technology, Goteborg, Sweden (1998).

16. Pope, S.B. "Computationally efficient implementation of combustion chemistry using in situ adaptive tabulation," Combust. Theory \& Modelling 1:41-63 (1997).

17. Veljkovic, I., P. Plassmann and D. Haworth, "A scientific on-line database for efficient function approximation," in Computational Science and Its Applications ICCSA 2003, Lecture Notes in Computer Science (LNCS 2667), Part I, pp. 643-653, Springer Verlag (2003).

18. Aroonsrisopon, T., P. Werner, J.O. Waldman, V. Sohm, D.E. Foster, T. Morikawa, and M. Iida, "Expanding the HCCI operation using the charge stratification," SAE paper 2004-01-1756 (2004).

19. Zhang, Y.Z., "Hybrid Particle/Mesh PDF Methods for 3D Time-Dependent Flows in Complex Geometries," Ph.D. Thesis, Department of Mechanical \& Nuclear Engineering, The Pennsylvania State University (2004).

20. Zhang, Y.Z., E.H. Kung and D.C. Haworth, "A PDF method for multidimensional modeling of HCCI engine combustion: effects of turbulence/chemistry interactions on ignition timing and emissions," Proc. Combust. Institute 30 (2004), to appear.

\section{FY 2004 Publications/Presentations}

UW DOE HCCI Working Group Presentation Meetings: January 29, 2004 (Sandia) and June 24, 2004 (USCAR). 
Kong, S.-C., and Reitz, R.D., "3-D CFD Tools for PCCI Engine Simulations," SAE Homogeneous Charge Compression Ignition Symposium, Berkeley, CA, August 10-11, 2004.

Foster, D.E., "The Impact of Stratification on HCCI Operational Ranges" SAE Homogeneous Charge Compression Ignition Symposium, Berkeley, CA, August 10-11, 2004.

Kong, S.-C., Patel, A., and Reitz, R.D., "Development and Application of Detailed Chemistry-Based CFD Models for Diesel HCCI Engine Combustion Simulations," Proceedings of THIESEL 2004 Conference, Valencia, Spain, September 9-12, 2004. Jhavar R., Rutland C.J., "A Computational Study of the Impact of Mixing on HCCI", Proceedings of THIESEL 2004, Universidad Politecnica De Valencia, Spain, September 2004.

Tao, F., Reitz, R.D., Srinivas, S., and Foster, D.F., "Current Status of Soot Modeling Applied to Diesel Combustion Simulations," COMODIA 2004, The Sixth International Symposium on Diagnostics and Modeling of Combustion in Internal Combustion engines, Yokohama, Japan, August 2 5, 2004.

Ra, Y., and Reitz, R.D., "The Role of Vaporization and Mixture Preparation on HCCI engine Combustion," ILASS-04 Conference, Washington, DC, May 16-19, 2004.

Hruby, E.J., Ra, Y., and Reitz, R.D., "Parametric Study of Combustion Characteristics in a Diesel HCCI Engine with a Low Pressure Fuel Injector," ILASS-04 Conference, Washington, DC, May 16-19, 2004.

Canakci, M., and Reitz, R.D., "Experimental Optimization of a DI-HCCI-Gasoline Engine's Performance and Emissions Using Split Injections with Fully-Automated Micro-Genetic Algorithms," ASME Journal of Gas Turbines and Power, Vol. 126, No. 1, pp. 167-177, 2004.

Juneja, H., Ra, Y., and Reitz, R.D., "Optimization of Injection Rate Shape using Active Control of Fuel Injection," SAE paper 2004-01-0530, Presented at SAE Congress, Detroit, MI, 2004.

Patel, A., Kong, S.-C., and Reitz, R.D., "Development and Validation of a Reduced Reaction Mechanism for HCCI Engine Simulations," SAE Paper 2004-01-0558, Presented at SAE Congress, Detroit, MI, 2004.

2010 ERC Diesel Emissions Reduction Consortium, Madison, WI, September 21, 2004.

Lee, K., and Reitz, R.D., "Investigation of Spray Characteristics from a Low-Pressure Common Rail Injection System for use in a HCCI Engine," Measurement Science and Technology, Vol. 15, No. 3, pp. 509-519, 2004.

Volker, S, Kong, S.C., Foster, D.E., Morikawa, T., Iida, M., "A Computational Investigation into the Cool Flame Region in HCCI Combustion," SAE $2004-01$ - 0552, Transactions, Presented at SAE Congress, Detroit, MI, 2004.

Aroonsrisopon, T, Werner, P., Sohm, V., Waldman, J., Foster, D.E., Morikawa, T, and Iida, M., "Expanding the HCCI Operation with Charge Stratification," SAE 2004 - 01 1756, Transactions, Presented at SAE Congress, Detroit, MI, 2004.

Zhang, Y.Z., "Hybrid Particle/Mesh PDF Methods for 3D Time-Dependent Flows in Complex Geometries," Ph.D. Thesis, Department of Mechanical \& Nuclear Engineering, The Pennsylvania State University (2004). 
Zhang, Y.Z., E.H. Kung and D.C. Haworth, "A PDF method for multidimensional modeling of HCCI engine combustion: effects of turbulence/chemistry interactions on ignition timing and emissions," Proc. Combust. Institute 30 (2004), to appear.

Veljkovic, P.E. Plassmann and D.C. Haworth, "Parallel implementation of scientific online database for efficient function approximation," 2004 Intern'l. Conference on Parallel and Distributed Processing Techniques and Applications, Las Vegas, NV (21-24 June 2004).

Zhang, Y.Z., E.H. Kung and D.C. Haworth, "A PDF method for three-dimensional timedependent computations of HCCI engine autoignition and emissions," SIAM $10^{\text {th }}$

International Conference on Numerical Combustion, Sedona, AZ (9-12 May 2004).

Haworth, D.C., "A PDF method for multidimensional modeling of HCCI engine combustion," CD-adapco $5^{\text {th }}$ ICE Work-Group Meeting, London, England (17 March 2004).

Haworth, D.C., "Combustion in internal combustion engines," STAR-CD $12^{\text {th }}$ European User Conference, London, England (15-16 March 2004).

Zhang, Y.Z., E.H. Kung and D.C. Haworth, "A PDF method for multidimensional modeling of HCCI engine combustion: effects of turbulence/chemistry interactions on ignition timing and emissions," $14^{\text {th }}$ International Multidimensional Engine Modeling Users' Group Meeting, Detroit, MI (7 March 2004).

Veljkovic, I., D.C. Haworth and P.E. Plassmann, "Parallel implementation of scientific on-line database," SIAM Conference on Parallel Processing for Scientific Computing, San Francisco, CA (25-27 February 2004).

\section{Special Recognitions \& Awards/Patents Issued}

Reitz R.D., Rutland C.J., Jhavar R., "Engine Valve Actuation for Combustion Enhancement”, Awarded U.S. Patent 6,736,106, May 2004.

\section{Acronyms}

atdc After Top Dead Center of compression btdc Before Top Dead Center of compression CFD Computaional Fluid Dynamics

CFR Cooperative Fuels Research

CO Carbon Monoxide

DI Direct Injection

EGR Exhaust Gas Recirculation

ERC Engine Research Center

GDI Gasoline Direct Injection

GT Gamma Technologies

HC Hydrocarbon

HCCI Homogeneous Charge Compression

Ignition

IMEP Indicated Mean Effective Pressure
IVC Intake Valve Closure
LES Large Eddy Simulation
PDF Probability Density Function
PFI Port Fuel Injection
PRF Primary Reference Fuel
RANS Reynolds Averaged Navier Stokes
RSM Response Surface Method
SOI Start of Injection
TCI Turbulence Chemistry Interaction
TRLC Top Ring Land Crevice
UHC Unburned Hydrocarbon
VGS Variable Geometry Spray

IMEP Indicated Mean Effective Pressure

LES Large Eddy Simulation

PDF Probability Density Function

PFI Port Fuel Injection

PRF Primary Reference Fuel

RSM Response Surface Method

SOI Start of Injection

TCI Turbulence Chemistry Interaction

TRLC Top Ring Land Crevice

VGS Variable Geometry Spray 


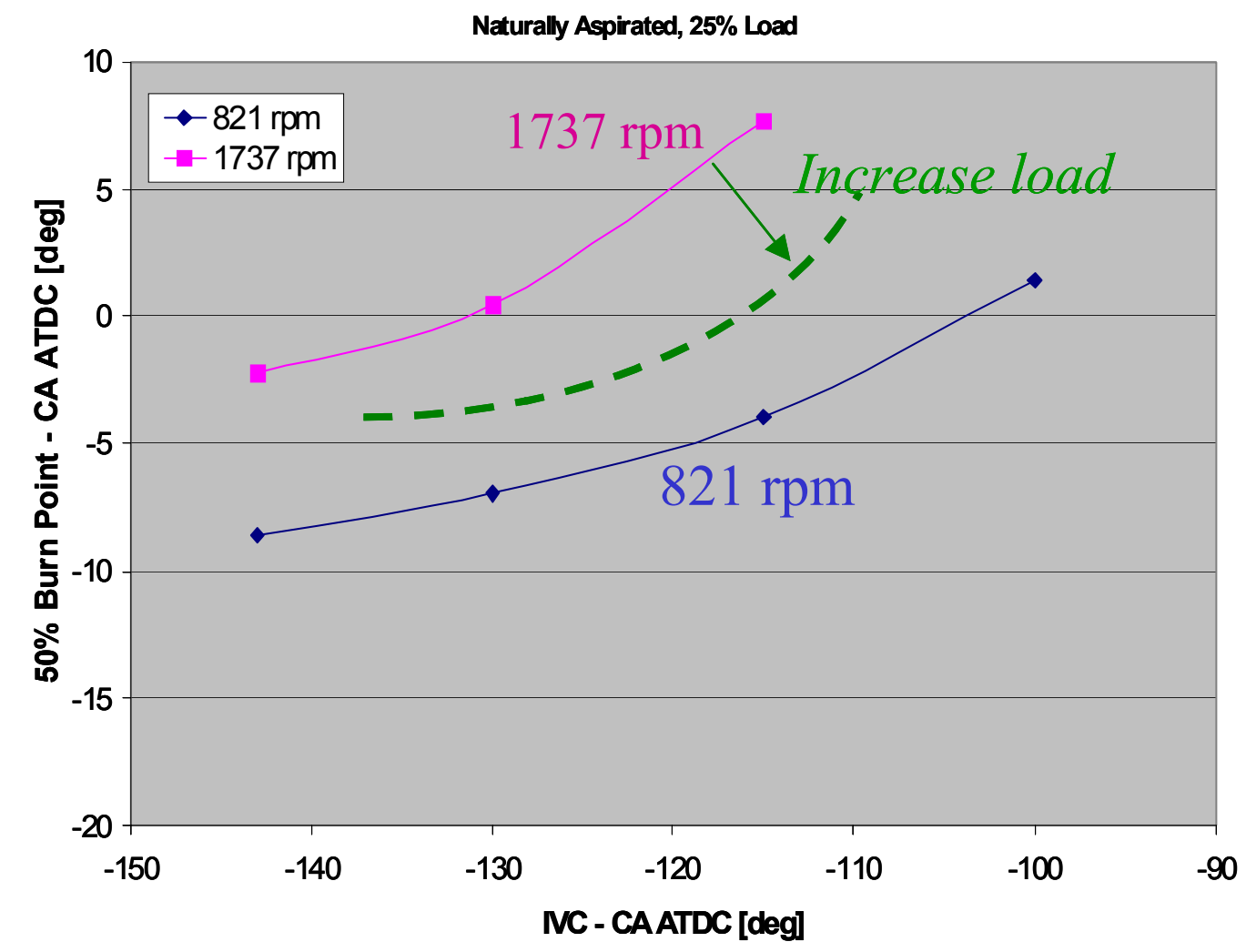

Figure 1. Combustion phasing control with variable valve timing. 50\% burn point versus IVC for different engine speeds and loads. 


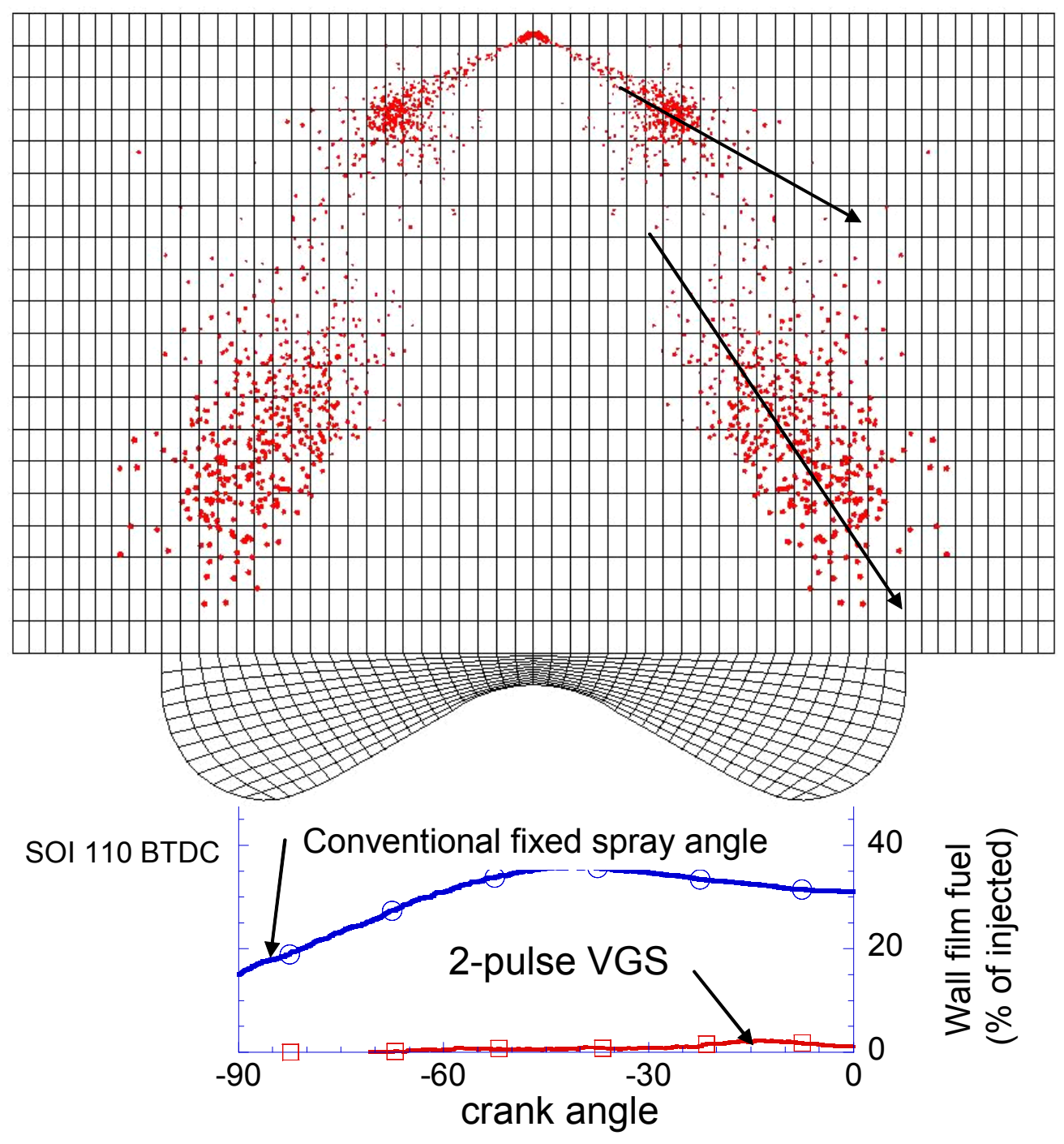

Figure 2. Optimized spray angle in each injection pulse gives improved fuel-air mixing, and significantly reduced impinged fuel during the compression and combustion processes 


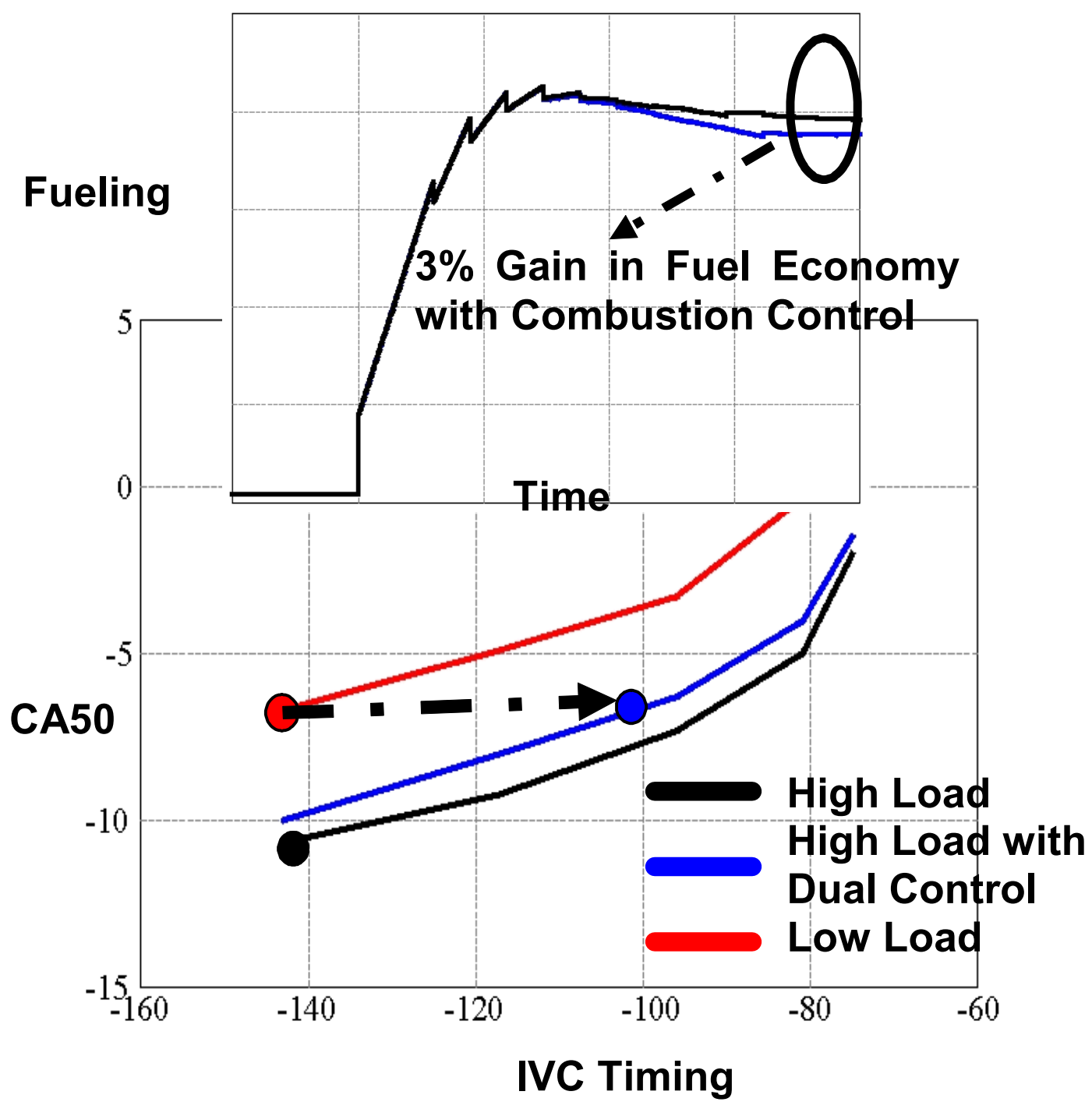

Figure 3. Simulation of load transient using simultaneous closed-loop control of fuel mass injected and variable intake valve closure. The use of variable valve closure demonstrates a 3\% improvement in fuel economy. 


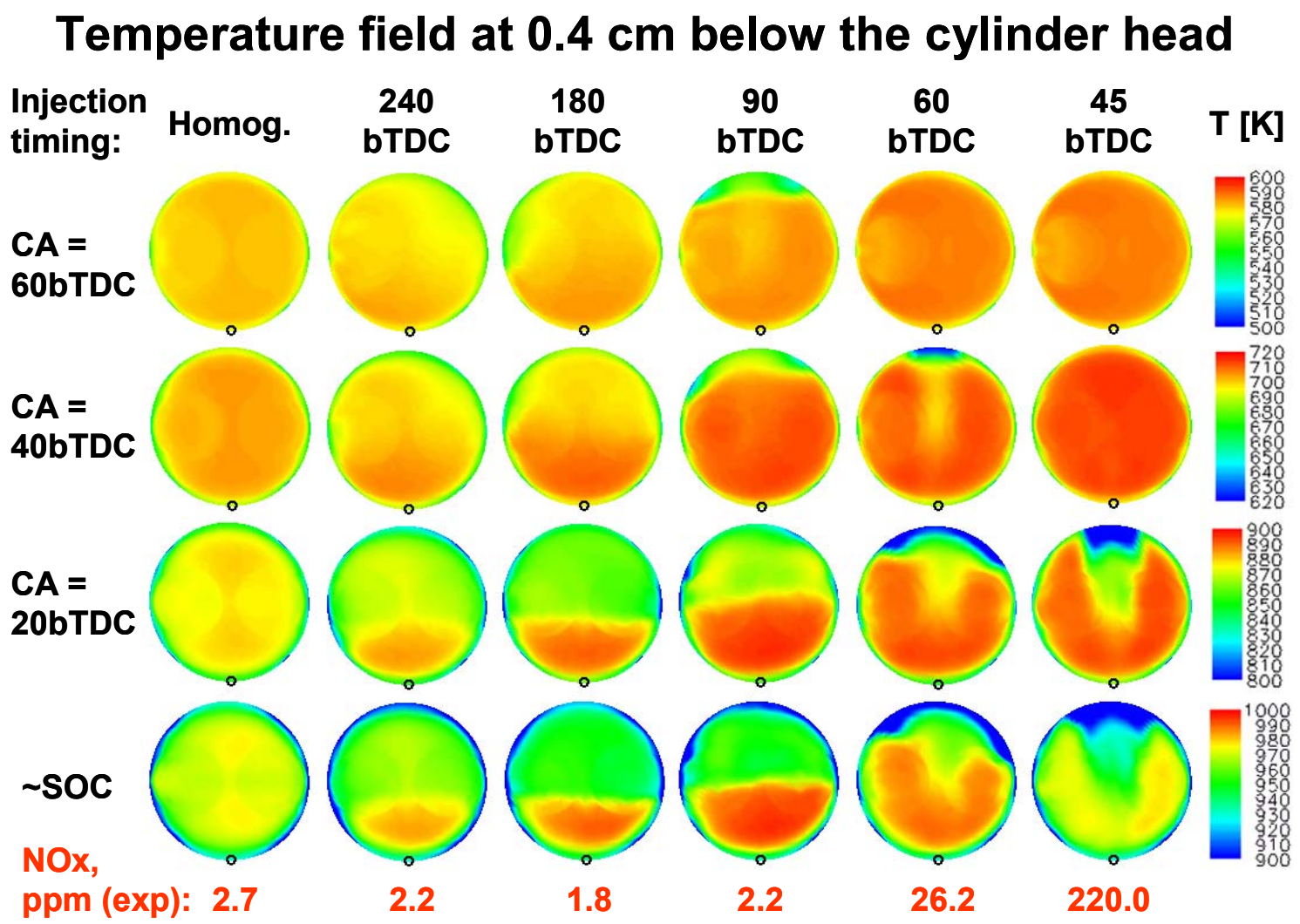

Figure 4. Predicted temperature distributions at different crank angles in a cut plane at the injector location for different SOI. The engine-out NOx for each operating condition is given at the bottom of each column of images. 


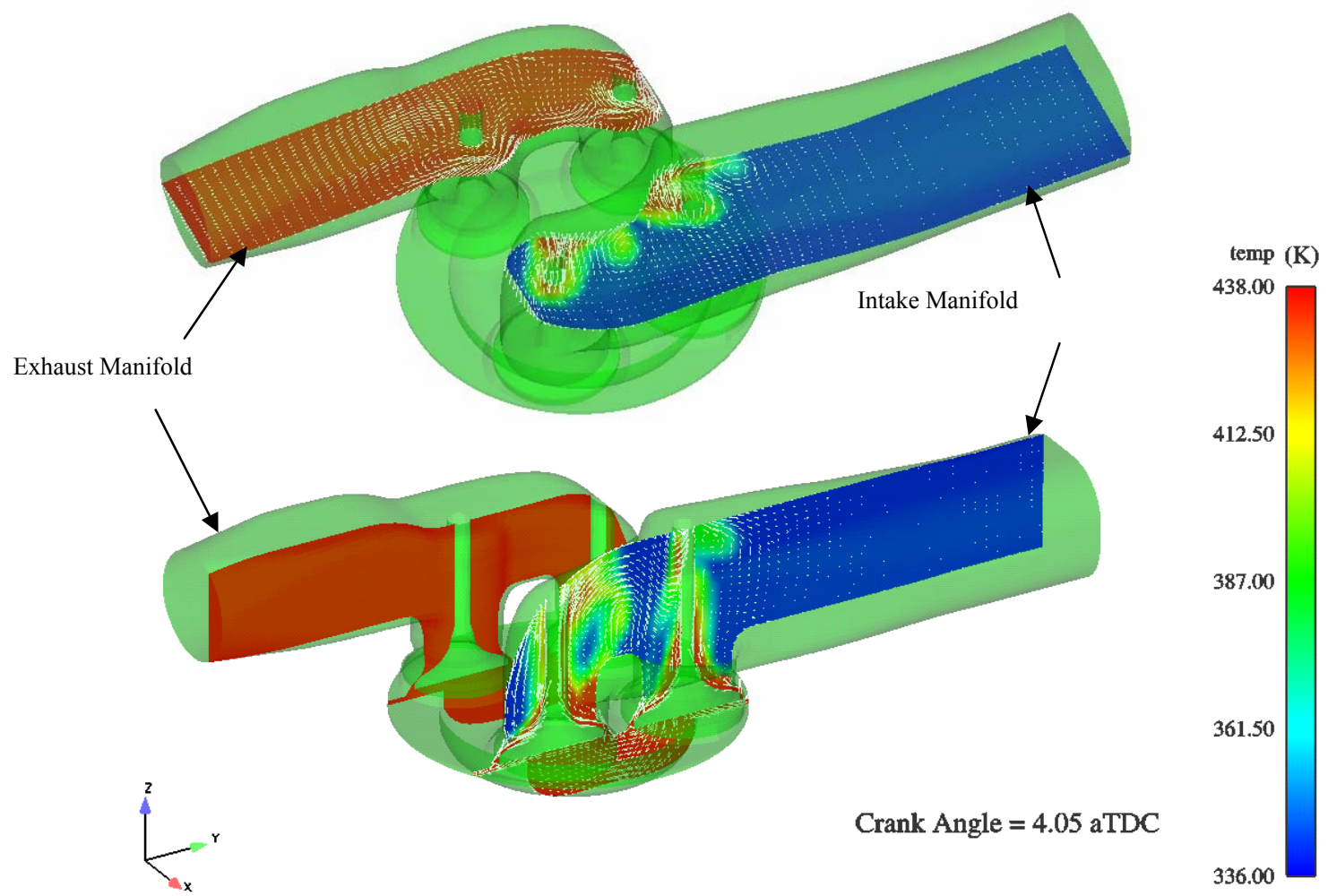

Figure 5. Cut-plane sections showing temperature contours through cylinder, intake and exhaust manifolds close to start of the intake stroke using LES turbulence models
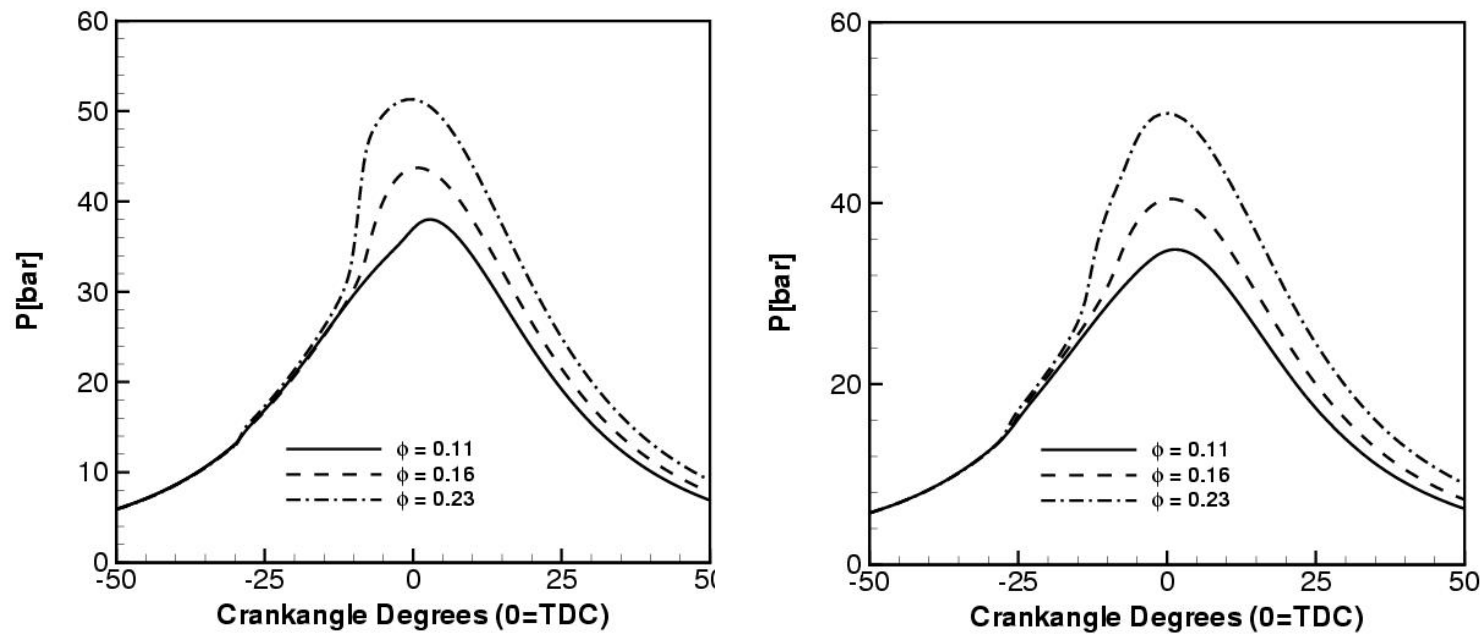

Figure 6. Computed (left) and measured (right) in-cylinder pressure with variations in equivalence ratio $\Phi$ for premixed n-heptane/air in the CFR engine. From Ref. [18]. 